\title{
A small-molecule inhibitor targeting the AURKC-IKB $\alpha$ interaction decreases transformed growth of MDA-MB-231 breast cancer cells
}

\author{
Eun Hee Han ${ }^{1,2,6, *}$, Jin-Young Min 1,3,*, Shin-Ae Yoo ${ }^{1}$, Sung-Joon Park ${ }^{1}$, Yun-Jeong \\ Choe $^{1,2}$, Hee Sub Yun ${ }^{1}$, Zee-Won Lee ${ }^{1}$, Sun Woo Jin ${ }^{4}$, Hyung Gyun Kim ${ }^{4}$, Hye Gwang \\ Jeong ${ }^{4}$, Hyun Kyoung Kim ${ }^{5}$, Nam Doo Kim ${ }^{5}$ and Young-Ho Chung ${ }^{1,3,6}$ \\ ${ }^{1}$ Drug \& Disease Target Research Team, Division of Bioconvergence Analysis, Korea Basic Science Institute (KBSI), Cheongju \\ 28119, South Korea \\ ${ }^{2}$ Immunotherapy Convergence Research Center, Korean Research Institute of Bioscience and Biotechnology (KRIBB), \\ Daejeon 34141, South Korea \\ ${ }^{3}$ Graduate School of Analytical Science and Technology (GRAST), Chungnam National University, Daejeon 34134, South \\ Korea \\ ${ }^{4}$ Department of Toxicology, College of Pharmacy, Chungnam National University (CNU), Daejeon 34133, South Korea \\ ${ }^{5}$ New Drug Development Center, Daugu Gyeoungbuk Medical Innovation Foundation (DGMIF), Daegu 41061, South Korea \\ ${ }^{6}$ Department of Bioanalytical Science, Korea University of Science and Technology (UST), Daejeon 34113, South Korea \\ *These authors have contributed equally to this work \\ Correspondence to: Young-Ho Chung, email: chungyh@kbsi.re.kr \\ Keywords: AURKC, protein-protein interaction, $I_{\kappa} B \alpha$, small-molecule inhibitor, breast cancer \\ Received: December 29, $2016 \quad$ Accepted: June 05, $2017 \quad$ Published: June 29, 2017 \\ Copyright: Han et al. This is an open-access article distributed under the terms of the Creative Commons Attribution License 3.0 \\ (CC BY 3.0), which permits unrestricted use, distribution, and reproduction in any medium, provided the original author and source \\ are credited.
}

\section{ABSTRACT}

The Aurora kinases, Aurora A (AURKA), Aurora B (AURKB), and Aurora C (AURKC), are serine/threonine kinases required for the control of mitosis (AURKA and AURKB) or meiosis (AURKC). Several Aurora kinase inhibitors are being investigated as novel anticancer therapeutics. Recent studies demonstrated that AURKC activation contributes to breast cancer cell transformation. Therefore, AURKC is both a promising marker and therapeutic target for breast cancer; however, its signaling network has not been fully characterized. Using translocation-based cellular assays, we identified IKB $\alpha$ as a binding partner of AURKC, and found that AURKC phosphorylates IKB $\alpha$ at Ser32, thereby activating it. In silico modeling and computational analyses revealed a small-molecule inhibitor (AKCI) that blocked the AURKC-IКB $\alpha$ interaction and exerted antitumor activity in MDA-MB-231 breast cancer cells. Specifically, AKCI induced G2/M cell-cycle arrest through modulation of the $\mathrm{p} 53 / \mathrm{p} 21 / \mathrm{CDC} 2 / \mathrm{cyclin} \mathrm{B} 1$ pathways. In addition, the drug significantly inhibited MDA-MB-231 cell migration and invasion, as well as decreasing colony formation and tumor growth. Via its interaction with $I_{\kappa} B \alpha$, AURKC indirectly induced NF- $K B$ activation; accordingly, AKCI decreased PMA-induced activation of NF-кB. Thus, the small-molecule inhibitor AKCI represents a first step towards developing targeted inhibitors of AURKC protein binding, which may lead to further advances in the treatment of breast cancer.

\section{INTRODUCTION}

Breast cancer is the most lethal of the femalespecific malignancies, as well as the most frequent cancer, with the second-highest mortality rate of all cancers in women worldwide [1]. The World Health Organization estimates that more than 1.2 million people are diagnosed with breast cancer each year [2]. Standard 
breast cancer therapy generally involves a combination of surgery, multi-therapeutic agents, and ionizing radiation [3].

Most current anticancer agents induce cell-cycle arrest and/or cell death via apoptotic or non-apoptotic mechanisms, including necrosis, senescence, autophagy, and mitotic catastrophe [4]. The Aurora kinases, a family of oncogenic serine/threonine kinases involved in the mitotic (M) phase of the cell cycle, participate in establishment of the mitotic spindle, bipolar spindle formation, alignment of centrosomes on the mitotic spindle, centrosome separation, cytokinesis, and monitoring of the mitotic checkpoint [3, 4-7]. These proteins are critical for accurate and organized division and segregation of chromosome to the daughter cells [7]. Consistent with their roles in promoting mitosis, they are often overexpressed in tumor cells, particularly those with high growth fractions [8]. In humans, three Aurora kinases (A, B, and C) are expressed in neoplastic and non-neoplastic tissues. Aurora A and B kinases (AURKA and AURKB) are expressed globally in all tissues, whereas Aurora $\mathrm{C}$ kinase (AURKC) is primarily expressed in testes, where it participates in meiosis [8]. Currently, several selective and nonselective Aurora kinase inhibitors are being tested in preclinical and clinical trials as antitumor agents [9]. Recent studies linked AURKC activity to tumorigenesis in somatic tissue, indicating that it may be a relevant cancer target $[10,11]$. AURKC induces abnormal cell division in cell lines, as well as tumor formation in nude mice [12]. Breast tumors often significantly overexpress AURKC in comparison with normal breast tissues [13]. Although AURKC is a potential anticancer drug target, no AURKC-specific inhibitors are currently in development, limiting our ability to elucidate AURKCspecific anticancer effects.

Protein-protein interactions (PPIs) are of pivotal importance in regulation of biological systems and their interfaces represent a highly promising, although challenging, class of potential targets for drug development [14-16]. In cancer, PPIs are signaling nodes and hubs that transmit pathophysiological cues, so efforts are constantly being made to target drugs, particularly PPIs [14]. Several small-molecule inhibitors that target allosteric PPI hotspots have recently been reported [16]. For example, PS210, identified by virtual screening for molecules targeting PDK1, can inhibit the PDK1/PIFtide interaction. ABT199, which targets the BCL2/Bcl$\mathrm{xL}$ interaction, is currently in phase 1 trials for chronic lymphocytic leukemia (CLL) [17].

In this study, we identified $\mathrm{I} \kappa \mathrm{B} \alpha$ as a PPI partner protein of AURKC, as well as a small-molecule inhibitor that targets the AURKC-I $\mathrm{B} \alpha$ interaction and interferes with the growth and tumorigenic activity of breast cancer cells.

\section{RESULTS}

\section{Identification of AURKC/IкB $\alpha$ molecular interactions}

To identify the binding partner of AURKC, we performed a cellular protein translocation-based screen using a GFP-tagging vector library in HEK293T cells. The library consists of GFP fusions of 597 kinases and kinaserelated genes, and was designed for analysis of PPI in cells by laser scanning fluorescence microscopy $[18,19]$. We focused the screen on kinases because they represent a set of readily druggable targets related to AURKC that are potentially amenable to clinical translation. Before PMA treatment, AURKC and $\mathrm{I} \kappa \mathrm{B} \alpha$ were localized in the cytoplasm. Following treatment with 300 nM PMA, both proteins relocalized to the plasma membrane due to the translocation properties of $\mathrm{PKC} \delta$. We found that $\mathrm{I} \kappa \mathrm{B} \alpha$ interacted with AURKC, as demonstrated by an increase in the ratio of cellular translocation in GFP-IאB $\alpha-$ transfected versus control vector-transfected wells (Figure

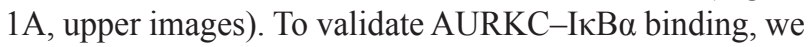
performed transfection in the opposite manner, i.e., with GFP-AURKC and PKC $\delta-m R F P-I \kappa B \alpha$ (Figure $1 \mathrm{~A}$, lower images). In addition, we confirmed the AURKC-I $\kappa \mathrm{B} \alpha$ interaction using the same technique in $\mathrm{CHO}-\mathrm{K} 1$ cells (Supplementary Figure 1). Furthermore, we evaluated the specificity of the AURKC-I $\kappa \mathrm{B} \alpha$ interaction by individually replacing the plasmids encoding each partner with empty vector (Supplementary Figure 2A, 2B, 2C).

To confirm the physical interaction between AURKC and I $\kappa \mathrm{B} \alpha$, we performed co-immunoprecipitation (co-IP) experiments using whole-cell extracts from HEK293T cells. Lysates from cells overexpressing fulllength AURKC and $\mathrm{I} \kappa \mathrm{B} \alpha$ were immunoprecipitated with I $\kappa \mathrm{B} \alpha$ or AURKC antibody or normal IgG, and the immunoprecipitates were subjected to $10 \%$ SDS-PAGE and Western blot analysis with anti-AURKC and anti-IкB $\alpha$ antibodies. As shown in Figure $1 \mathrm{~B}, \mathrm{I} \kappa \mathrm{B} \alpha$ and AURKC reciprocally co-precipitated in HEK293T cells when using a specific antibody against either protein, but not normal IgG. To further confirm the interaction, we performed a mammalian two-hybrid assay using the pGC-luc, BindAURKC, and Act-IкB $\alpha$ plasmids. Luciferase activity, representing binding of AURKC and $\mathrm{I} \kappa \mathrm{B} \alpha$, was about 2.7fold higher than that of the Bind-AURKC vector (Figure 1C). This result indicated that AURKC interacts with I $\mathrm{B} \alpha$ in mammalian cells. Furthermore, to confirm the binding of AURKC and $\mathrm{I} \kappa \mathrm{B} \alpha$ in vivo, we performed a proximity ligation assay (PLA) using the Duo-Link kit. Interactions between AURKC and $\mathrm{I} \kappa \mathrm{B} \alpha$ appeared as red dots in cellular images. Red dots were not detected in untreated controls or in cells treated with one antibody alone. By contrast, in samples exposed to both kinds of antibodies, red dots were observed, confirming the interaction between the 
A

(-) PMA
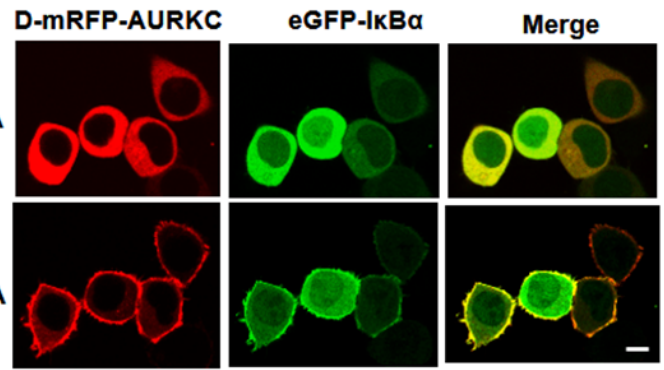

(-) PMA
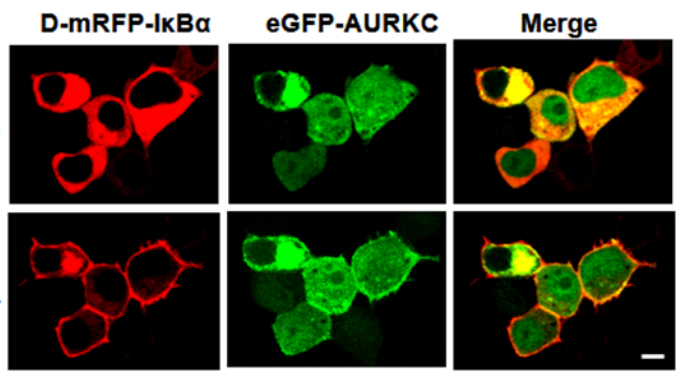

B

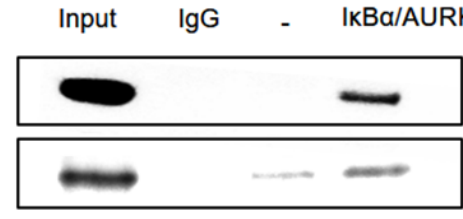

IP: IKBa

IB: AURKC

(+) PMA
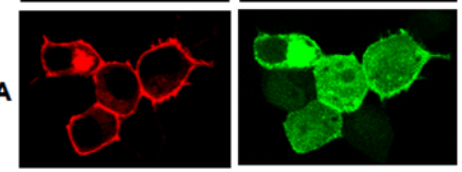

IP: AURKC

IB: IKBa

C

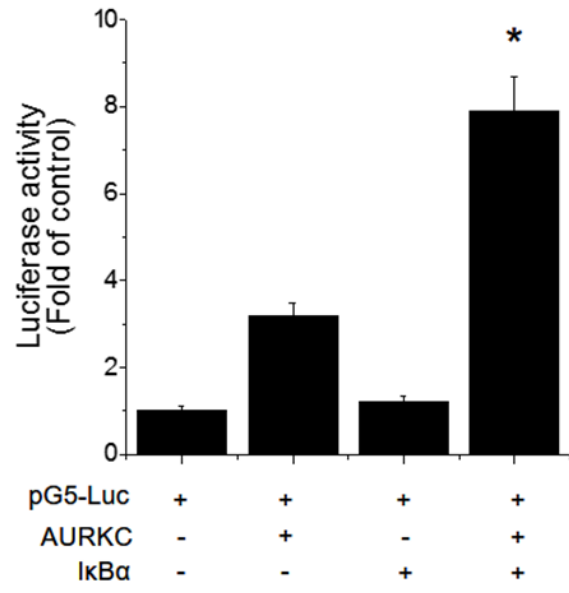

D

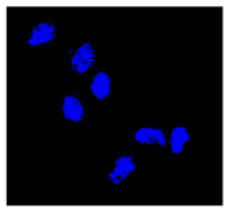

Control

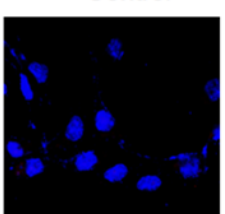

AURKC

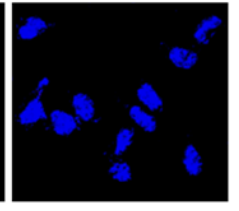

IKBa

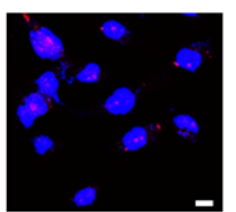

IKBa/AURKC
Scale bar: $10 \mu \mathrm{m}$

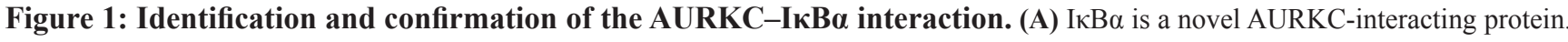

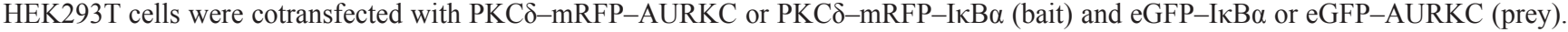
Before PMA treatment, the mRFP-tagged bait and GFP-tagged prey proteins were localized in the cytoplasm. However, after PMA (300 nM) was added, bait and prey proteins were relocalized to the plasma membrane due to the translocation properties of PKC $\delta$. Scale bar, $10 \mu \mathrm{m}$. (B) Immunoblotting to confirm the interaction. Whole-cell lysates of HEK293T cells transfected with AURKC and IкB $\alpha$ were subjected to immunoprecipitation with either IgG (negative control) or anti-AURKC antibody, followed by Western blot of the immunoprecipitates with anti-I $\kappa \mathrm{B} \alpha$ antibody. (C) Interaction between proteins expressed from $\mathrm{pM-BD-pAURKC}$ and $\mathrm{pVP}-\mathrm{I} \kappa \mathrm{B} \alpha$ was assessed using the mammalian two-hybrid $(\mathrm{M} 2 \mathrm{H})$ assay. Luciferase activity indicates the change in relative luminescence units, normalized against the negative control. * $P<0.01$, significantly different from control as determined by analysis of variance (Newman-Keuls test). (D) PLA for detection of binding of AURKC and IкB $\alpha$ in HEK293T cells, performed using the Duo-Link kit (magnification, 40×; scale bar, $10 \mu \mathrm{m}$ ). Nuclei are stained with DAPI (blue); Duo-Link signals are shown in red. Each red dot represents a single AURKC-IкB $\alpha$ molecular interaction event. 
two proteins (Figure 1D). Comparisons of the counts of red dots in images confirmed that AURKC bound I $\mathrm{B} \alpha$ in HEK293T cells. Taken together, these binding analysis results provide evidence supporting an interaction between $\mathrm{AURKC}$ and $\mathrm{I} \kappa \mathrm{B} \alpha$ in vitro and in vivo.

\section{IKBa is involved in AURKC-mediated transformation in invasive breast cancer cells}

Nuclear factor- $\kappa \mathrm{B}(\mathrm{NF}-\kappa \mathrm{B})$ is a family of highly regulated dimeric transcription factors that play pivotal roles in cancer cell transformation. I $\kappa \mathrm{B} \alpha$ was originally thought to retain $\mathrm{NF}-\kappa \mathrm{B}$ dimers in the cytoplasm by masking their nuclear localization sequences (NLSs) [20]. Aberrant NF- $\kappa \mathrm{B}$ activation in tumor cells results from genetic changes or activation of $\mathrm{NF}-\kappa \mathrm{B}$ pathways by indirect (i.e., I $\kappa \mathrm{B} \alpha$-mediated) mechanisms. We next examined the functional significance of the interaction between AURKC and I $\mathrm{B} \alpha$. AURKC is overexpressed in invasive breast cancer cells and exerts oncogenic activity $[10,11]$, but the precise underlying mechanisms remain unknown. Because $\mathrm{I} \kappa \mathrm{B} \alpha$ is a binding partner of AURKC, as demonstrated above, we hypothesized that AURKC-induced I $\kappa \mathrm{B} \alpha$ activation modulates NF$\kappa \mathrm{B}$ activity. The results of $\mathrm{NF}-\kappa \mathrm{B}$ promoter-reporter assays revealed that AURKC overexpression did not induce NF-kB activation; however, PMA-induced $\mathrm{NF}-\kappa \mathrm{B}$ promoter activity was elevated in AURKCoverexpressing cells (Figure 2A). Thus, I $\mathrm{BB} \alpha$ might be involved in AURKC-induced transformation in AURKC-overexpressing breast cancer cells. To test this idea, we established AURKC- and shRNAAURKC-expressing MDA-MB-231 cells using a lentivirus system, and subjected them to soft agar assays. MDA-MB-231 is an invasive breast cancer cell line, and its growth rate increases rapidly when AURKC is overexpressed (data not shown). Induced anchorage-independent growth was more prominent in AURKC-expressing MDA-MB-231 cells than in empty vector and scrambled shRNA overexpressing cells. In addition, anchorage-independent growth was reduced in both AURKC-overexpressing MDA-MB-231 cells treated with $\mathrm{I} \kappa \mathrm{B} \alpha$ inhibitor and AURKC-knockdown cells (Supplementary Figure 4 for validation of AURKC knockdown by shRNA) (Figure 2B). To further support our observations, we performed colony-forming assays using $\mathrm{I} \kappa \mathrm{B} \alpha$ inhibitor and the reference compound GSK1070916, an ATP-competitive inhibitor of AURKC. To confirm the synergistic effect of the two inhibitors, cells were treated at $1 / 10$ th of the respective inhibitory concentrations of each compound. When both inhibitors were present, the number of colonies was much smaller than when cells were treated with either compound alone (Figure 2C). These results confirmed our hypothesis that $\mathrm{I} \kappa \mathrm{B} \alpha$ is related to the AURKC-induced transformation in MDA-MB-231 breast cancer cells.

\section{AURKC phosphorylates IKB $\alpha$ on $\mathrm{S32}$ and binds its ankyrin repeat domain}

Because AURKC is a serine-threonine kinase, we hypothesized that phosphorylation might modulate

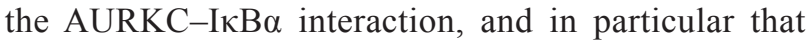
AURKC might activate $\mathrm{I} \kappa \mathrm{B} \alpha$. Phosphorylation of $\mathrm{I} \kappa \mathrm{B} \alpha$ at $\mathrm{S} 32 / \mathrm{S} 36$ precedes its dissociation from $\mathrm{p} 65$ $\mathrm{NF}-\kappa \mathrm{B}$, allowing it to translocate into the nucleus and activate transcription from target promoters. Cell-based phospho-I $\kappa \mathrm{B} \alpha$ ELISA revealed that AURKC activated I $\mathrm{B} \alpha$, whereas AURKC shRNA decreased I $\mathrm{B} \alpha$ activity, in HEK293 cells (Figure 3A). To investigate the precise mechanism, we performed in vitro protein kinase assays with activated AURKC kinase and purified $\mathrm{I} \kappa \mathrm{B} \alpha$ protein using the HaloTag system (Promega). I $\mathrm{B} \alpha$ phosphorylation was increased by active AURKC, and this phosphorylation was slightly lower than IKK $\beta$ with known $\mathrm{I} \kappa \mathrm{B} \alpha$ activator (Figure $3 \mathrm{~B}$ ). As shown in Figure $3 \mathrm{C}$, AURKC induced phosphorylation of the $\mathrm{I} \kappa \mathrm{B} \alpha$ mutant S36A, but not S32A or the S32/36 dual mutant. Therefore, I $\mathrm{B} \mathrm{B} \alpha$ phosphorylation in $\mathrm{S} 32$ is important for the interaction with AURKC protein. As a positive control, we used IKK $\beta$, which phosphorylates IкB $\alpha$ on serine 32 and 36. These results indicate that AURKC induces site-specific phosphorylation of $\mathrm{I} \kappa \mathrm{B} \alpha$.

To identify the interacting domains of $\mathrm{I} \kappa \mathrm{B} \alpha$ and AURKC, we designed various deletion constructs of $\mathrm{I} \kappa \mathrm{B} \alpha$. Plasmids encoding the corresponding fragments of $\mathrm{I} \kappa \mathrm{B} \alpha$ were constructed, and each I $\mathrm{K} \mathrm{B} \alpha$ fragment was purified using the HaloTag system. In vitro protein kinase assays revealed that AURKC phosphorylated full-length I $\kappa \mathrm{B} \alpha(1-317$ aa) as well as the $1-175$ aa and $1-277$ aa truncations. However, an internal deletion of $\mathrm{I} \kappa \mathrm{B} \alpha$ (1-72/278-317 aa) was not phosphorylated by AURKC (Figure 3D). Therefore, the region containing residues 72 175 of $\mathrm{I} \kappa \mathrm{B} \alpha$ (ankyrin repeat domains 1-3) is important for phosphorylation by AURKC.

\section{His164 and Arg165 of AURKC interact with the $\mathrm{I} \kappa \mathrm{B} \alpha$ ankyrin repeat domain}

A model of the AURKC-I $\kappa \mathrm{B} \alpha$ complex obtained from protein-protein docking simulations suggested that AURKC bound to the region containing residues 73175 of I $\kappa \mathrm{B} \alpha$ (Figure 4A). The structure of the predicted AURKC-I $\kappa \mathrm{B} \alpha$ complex indicated that the activation loop of AURKC and ankyrin repeat domain of $\mathrm{I} \kappa \mathrm{B} \alpha$ are crucial for the interaction. Specifically, the model shows that His 164 and Arg165 of AURKC closely contact Val 97 and Lys 98 of I $\mathrm{B} \alpha$ (Figure 4A). To confirm this idea, we constructed a plasmid expressing AURKC protein with mutations at His164, and subjected the protein to co-IP experiments. HEK293T cells were cotransfected with GFP-tagged wild-type AURKC or AURKC H164Y, along with FLAG-tagged $\mathrm{I} \kappa \mathrm{B} \alpha$. Whole-cell lysates were 


\section{A}

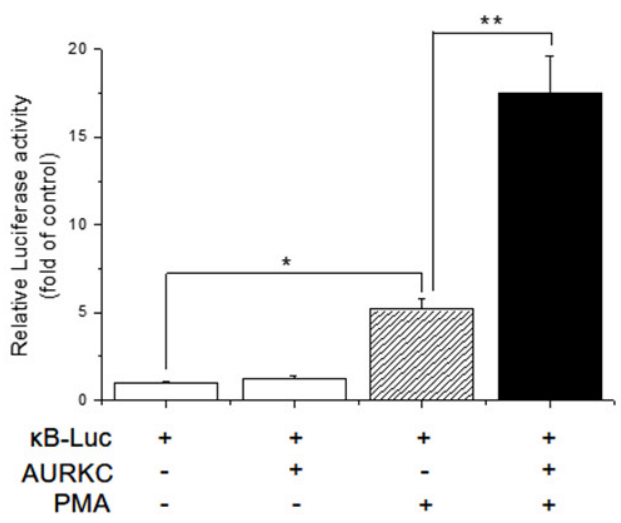

B

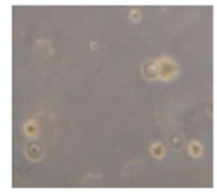

AURKC

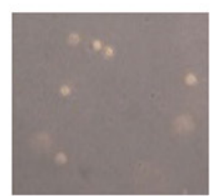

Empty vector

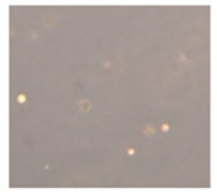

AURKC shRNA

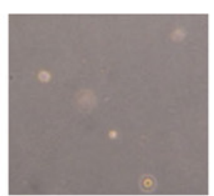

Scrambled shRNA

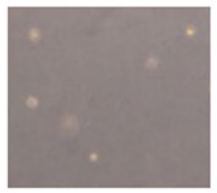

AURKC + IKBa inhibitor

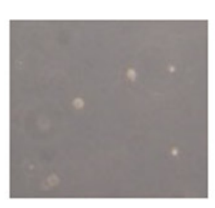

IKBa inhibitor

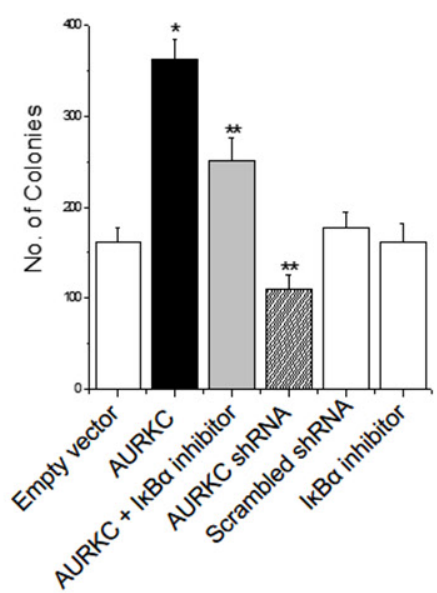

C
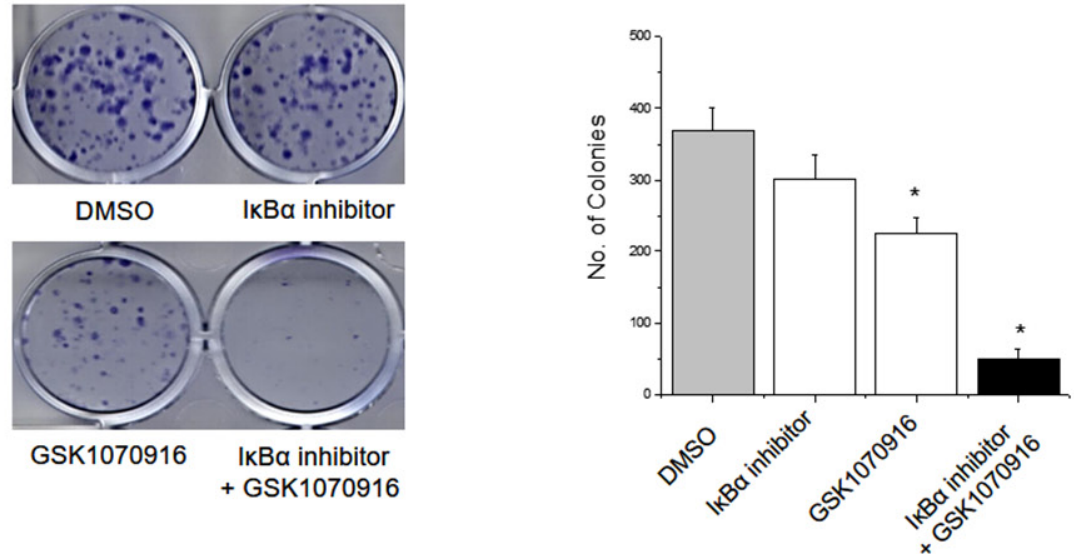

Figure 2: Effects of the AURKC-IкB $\alpha$ interaction on cellular transformation in breast cancer cells. (A) HEK293T cells were transiently cotransfected with $0.5 \mu \mathrm{g}$ of pGL3-NF- $\kappa B-l u c, 0.5 \mu \mathrm{g}$ of pcDNA3.1-AURKC, and $0.2 \mu \mathrm{g}$ of pCMV- $\beta$-gal. After $4 \mathrm{~h}$, the cells were treated with PMA $(100 \mathrm{nM})$ for $24 \mathrm{~h}$, and luciferase activity was normalized against $\beta$-galactosidase activity. ${ }^{*} P<0.01$ and $* *$ $P<0.01$, significantly different from control and PMA treatment, respectively. (B) Empty vector and AURKC stable MDA-MB-231 cell lines $\left(1 \times 10^{3}\right.$ cells $\left./ \mathrm{ml}\right)$ were mixed with $0.3 \%$ soft agar and grown on a $0.6 \%$ agarose base layer. Anchorage-independent colony formation was decreased by AURKC shRNA (stable cell lines \#2 and \#3) and IкB $\alpha$ inhibitor treatment. The number of colonies $\geq 50 \mu \mathrm{m}$ in diameter was counted 10 days after plating. Left panel, images of representative wells; right panel, graph. $* P<0.01$, significantly different from control as determined by analysis of variance (Newman-Keuls test). (C) The tumorigenic effect of AURKC and I $\mathrm{B} \alpha$ on colony formation of MDA-MB-231 cells. Cells were treated with IkB $\alpha$ inhibitor $(100 \mathrm{nM})$ or GSK1070916 $(1 \mathrm{nM})$ for 8 days. Representative images of colony-forming assay and analysis of colony formation rates are shown. Data are means $\pm \mathrm{SD}$ of three independent experiments. $* P<$ 0.01 vs. control group. 
A

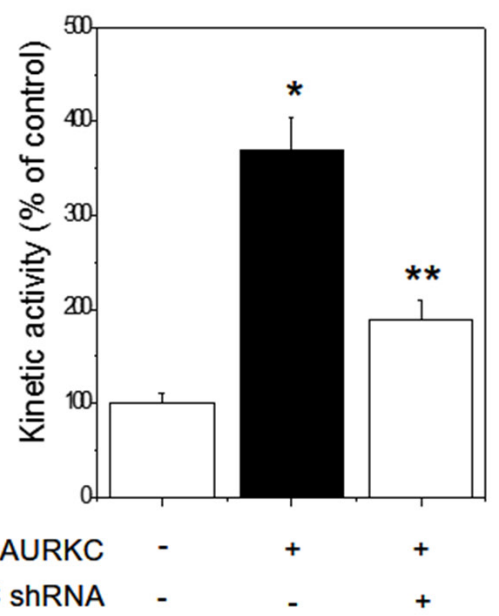

B

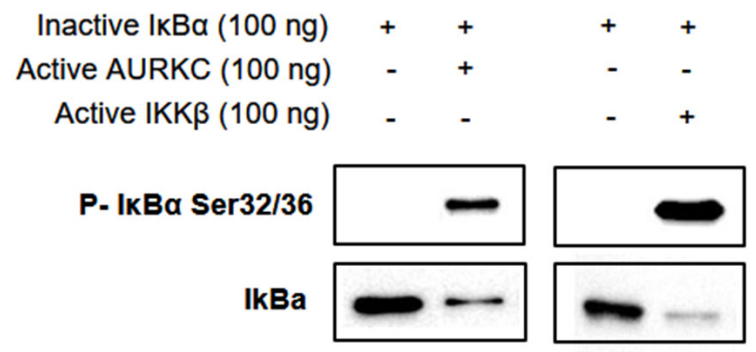

C

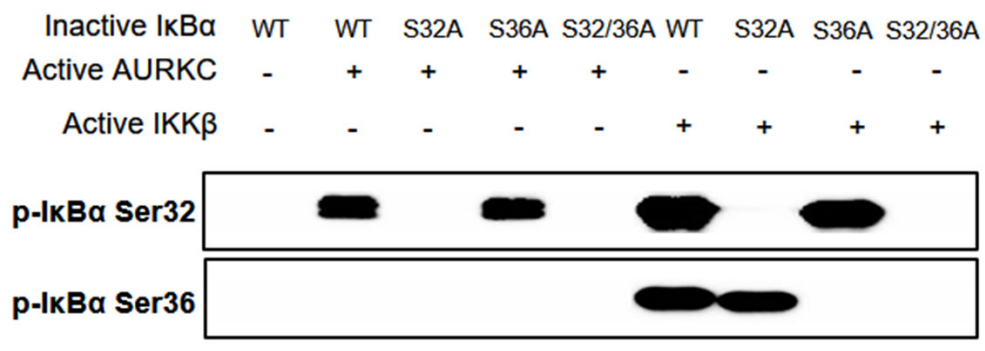

IKBa

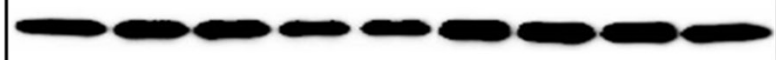

Figure 3: Effects of AURKC on IKB $\boldsymbol{\alpha}$ activation. (A) Cell-based IкB $\alpha$ activation assay. HEK293T cells were seeded in black 96well plates and then transfected with AURKC expression vector or shRNA (CCACGATAATAGAGGAGTTGGCAGATGCC) for $24 \mathrm{~h}$. * $P<0.01$ and $* * P<0.01$, significantly different from control and AURKC as determined by analysis of variance (Newman-Keuls test). (B) Purified inactive IאB $\alpha$ protein (WT, S32A, S36A, S32/36A mutant) and active AURKC or IKK $\beta$ protein were incubated for $30 \mathrm{~min}$, and then immunoblotted with IкB $\alpha$ S32 and S36 phospho-specific antibodies, as indicated. (C) Identification of the interacting domains

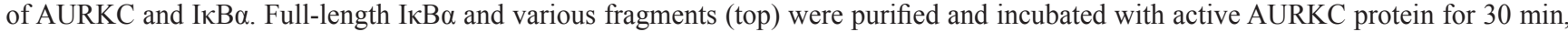

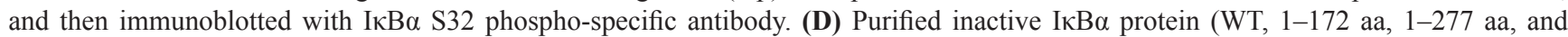
1-72/278-317 aa deletion mutant) and active AURKC protein were incubated for $30 \mathrm{~min}$, and then immunoblotted using an IкB $\alpha$ S32 phospho-specific antibody. 
subjected to immunoprecipitation with GFP antibody or normal IgG, followed by Western blot analysis with antiFLAG antibody. I $\kappa \mathrm{B} \alpha$ was efficiently co-precipitated with wild-type AURKC, but the AURKC H164Y mutation disrupted the interaction, as expected (Figure 4B). This result demonstrated that His 164 of AURKC is important for the interaction with $\mathrm{I} \kappa \mathrm{B} \alpha$ ankyrin repeat domains I/ II/III.

\section{A small-molecule PPI inhibitor that targets the AURKC-IKB $\alpha$ interaction}

Using docking-based virtual screening, we searched for an inhibitor of the AURKC-I $\kappa \mathrm{B} \alpha$ binding interface.
For this purpose, we used the ChemBridge compound library (http://www.chembridge.com), a commercially available database containing 728,435 molecules. The initial virtual screen for compounds capable of fitting the AURKC-I $\mathrm{B} \mathrm{B} \alpha$ binding pocket was performed using the HTVS and SP scoring functions of Glide (http://www. schrodinger.com). A total of 35 compounds were selected for further testing.

To test the activity of these compounds, we performed cellular protein translocation-based screen assays at non-cytotoxic doses, and identified one compound (AKCI, Figure 5A) that interrupted AURKC-I $\mathrm{B} \mathrm{B} \alpha$ binding with a half-maximal inhibitory concentration $\left(\mathrm{IC}_{50}\right)$ of $24.9 \mu \mathrm{M}$ (The $\mathrm{IC}_{50}$ values were

A

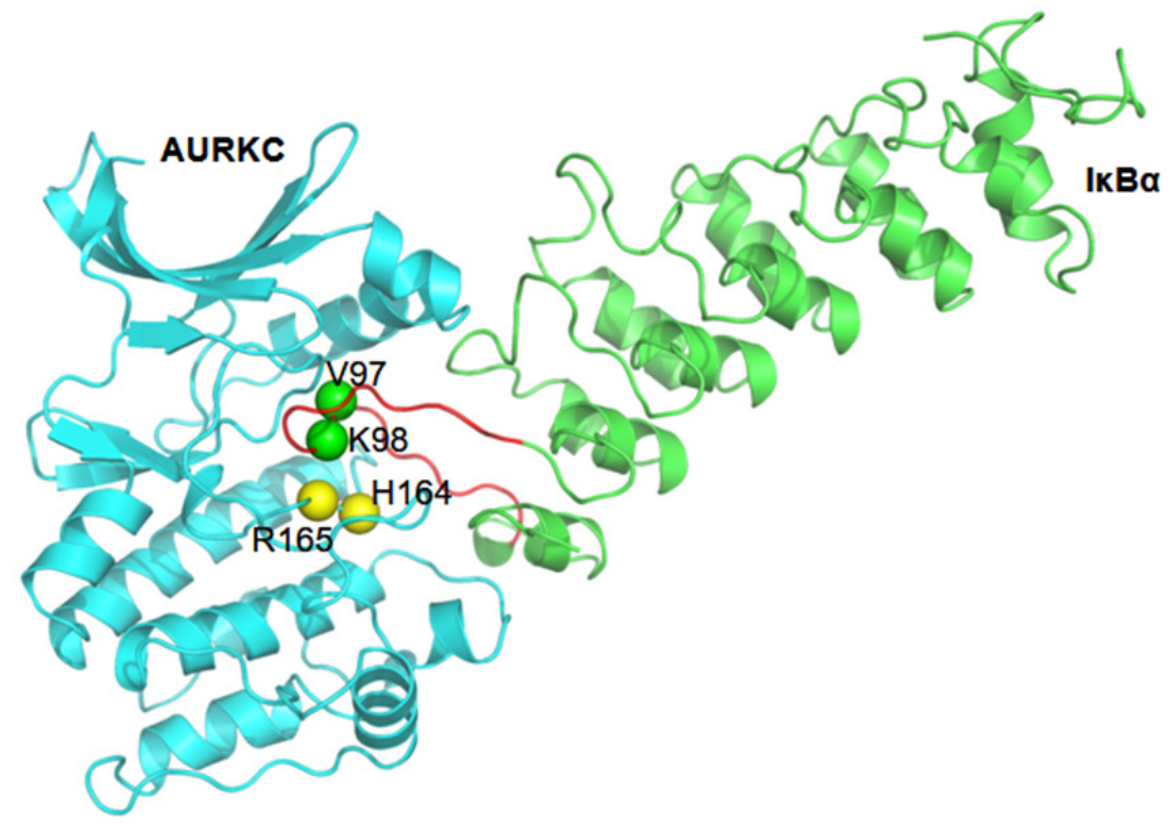

B

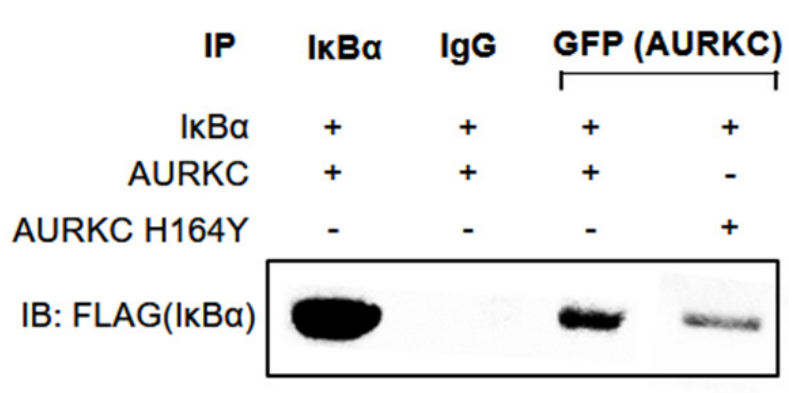

Figure 4: His164 of AURKC interact with IкBa. (A) Protein-protein interaction model of AURKC and IкB $\alpha$. The loop from Met

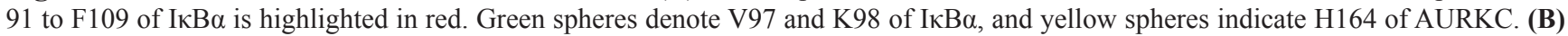
Results of a co-IP assay between I $\kappa \mathrm{B} \alpha$ and wild-type AURKC or the AURKC H164Y mutant. Representative blots are shown, and the results of three replications are quantified in the graph. 
calculated from the $\mathrm{M} 2 \mathrm{H}$ assay results). To further characterize the interactions between AKCI and AURKC, we performed a molecular docking study in which AKCI was docked into the AURKC-I $\mathrm{B} \alpha$ binding site using the Glide docking tool. As shown in Figure 5B, the 1,3,5-triazinyl of AKCI was predicted to form hydrogen-bonding interactions with Asp184 and His 164 of AURKC. In addition, a morpholino-ethyl group of AKCI was predicted to interact via hydrogen bonding with the Ile163 backbone of AURKC. These results provide support for the interaction between the activation loop of AURKC and ankyrin repeat domain of $\mathrm{I} \kappa \mathrm{B} \alpha$. The inhibitory effect of AKCI was evaluated in cellular protein translocation images in HEK293T cells. Upon PMA treatment, the bait (RFP-tagged AURKC or $\mathrm{I} \kappa \mathrm{B} \alpha$ ) was translocated to the cellular membrane (Figure 6A). When bait and prey (GFP-tagged $\mathrm{I} \kappa \mathrm{B} \alpha$ or AURKC) interact, the prey protein should also migrate to the membrane. However, migration did not occur in the presence of AKCI, suggesting that this compound disrupted the interaction (Figure 6A). The inhibitory effect of AKCI was confirmed using the same technique in CHO-K1 cells (Supplementary Figure 3). To confirm that $\mathrm{AKCI}$ inhibits binding between AURKC and $\mathrm{I} \kappa \mathrm{B} \alpha$,

\section{A}<smiles>Cc1nc(NC2=NCN(CCN3CCOCC3)CN2)nc2c(C)cccc12</smiles>

B

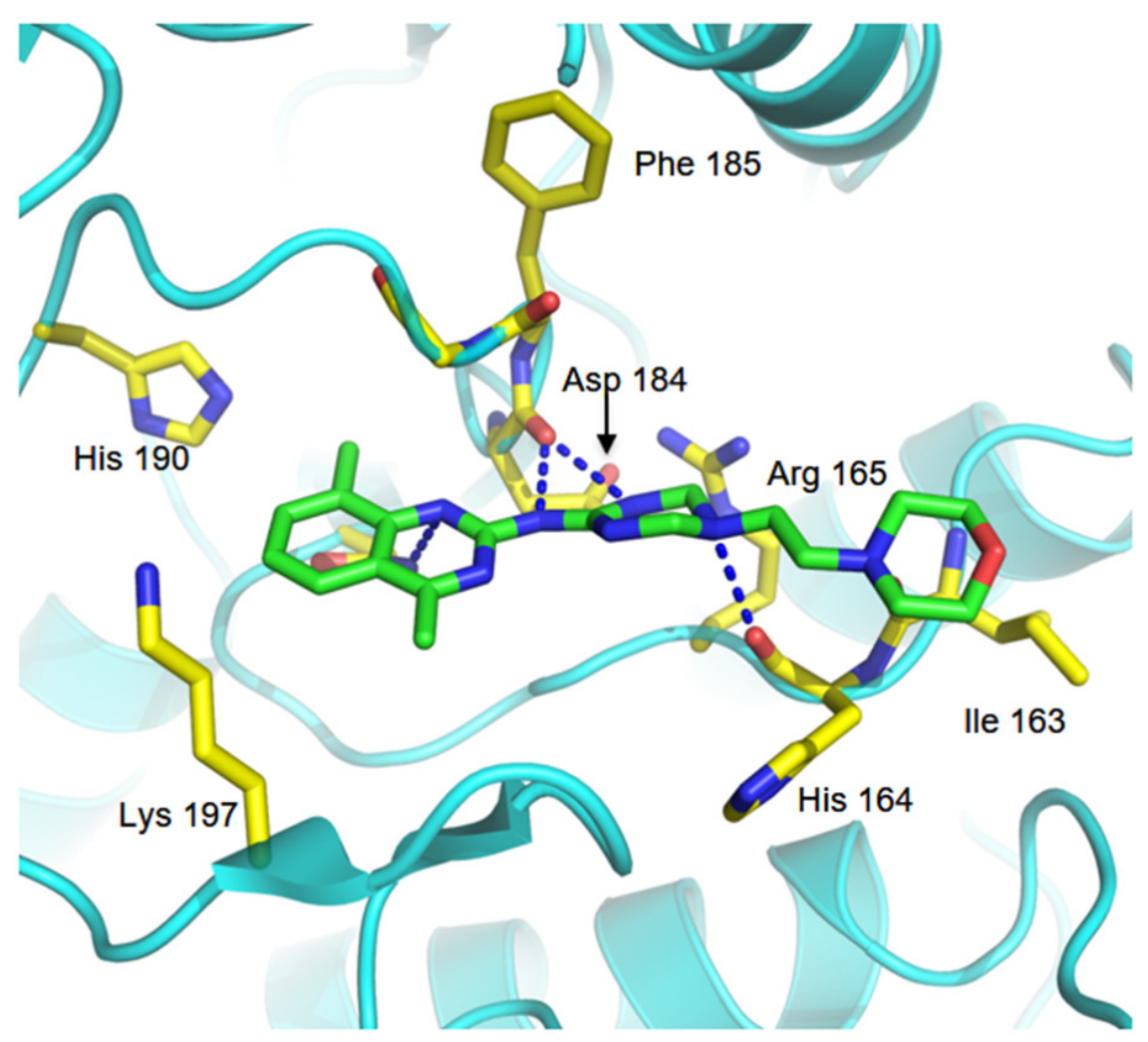

Figure 5: Binding model of AURKC and the IKB $\alpha$ interaction inhibitor (AKCI). (A) Structure of the small-molecule PPI inhibitor AKCI. (B) Proposed binding model of AURKC and AKCI. Dashed blue lines show hydrogen-bonding interactions between AKCI and the backbone of His164 and Phe185 and the side chain of Asp184. 
we performed co-IP and M2H assays. Lysates from HEK293T cells overexpressing full-length AURKC and $\mathrm{I} \kappa \mathrm{B} \alpha$, with or without AKCI, were subjected to immunoprecipitation with anti-AURKC antibody and Western blot analysis with anti-I $\mathrm{B} \alpha$. As shown in Figure 6B, AURKC was efficiently co-precipitated with $\mathrm{I} \kappa \mathrm{B} \alpha$ in the absence, but not the presence, of AKCI. $\mathrm{M} 2 \mathrm{H}$ assays were conducted using plasmids pGCluc, Bind-AURKC, and Act-I $\kappa \mathrm{B} \alpha$. At concentrations of 10 and $26 \mu \mathrm{M}$, AKCI decreased luciferase activity (Figure 6C), confirming that it blocked the AURKC-I $\kappa \mathrm{B} \alpha$ interaction. Moreover, AKCI inhibited recombinant AURKC-induced phosphorylation of $\mathrm{I} \kappa \mathrm{B} \alpha$ (Figure 6D).

Subsequent studies revealed that AKCI, which was identified using a docking-based virtual screening protocol targeting the AURKC-I $\mathrm{B} \alpha$ interaction, does not target the ATP-binding site of the kinase. For this purpose, we performed an ATP-competitive binding assay using AKCI and GSK1070916. The kinase-inhibitory activity of AKCI on AURKC was independent of the ATP concentration, whereas the inhibitory activity of GSK1070916 was inversely proportional to the concentration of ATP (Figure $6 \mathrm{E}$ and 6F). Therefore, unlike GSK1070916, AKCI inhibits the AURKC-I $\mathrm{B} \alpha$ interaction by interfering with protein-protein binding, rather than competitively inhibiting ATP binding.

To confirm the specificity of AKCI for AURKC, we performed in vitro kinase assays using recombinant AURKA, which is known to interact with $\operatorname{I} \kappa \mathrm{B} \alpha$ [21]. As shown in Figure $6 \mathrm{G}$, activation of $\mathrm{I} \kappa \mathrm{B} \alpha$ by AURKA was not altered by AKCI treatment. Thus, AKCI is a specific inhibitor of the interaction between AURKC and $\mathrm{I} \kappa \mathrm{B} \alpha$.

\section{AKCI exerts an anticancer effect and induces G2/M arrest in MDA-MB-231 breast cancer cells}

To determine whether AKCI exerts an anticancer effect by targeting AURKC protein in MDA-MB-231 breast cancer cells, we performed migration, invasion, and colony formation assays. As shown in Figure 7A, AKCI markedly decreased the migration of highly invasive MDA-MB-231 cells in a concentration-dependent manner. In addition, the inhibitor significantly decreased the number of invading cells following treatment with PMA (Figure 7B). Likewise, AKCI treatment diminished colony formation (Figure 7C). Breast tumors express significantly higher levels of AURKC than normal breast tissues, and the $A U R K C$ gene is amplified in MDA-MB-231 cells [22]. The protein affects cell division via its serine/threonine kinase activity and its capacity to organize microtubules in relation to centrosome/spindle function during mitosis [13]. Western blot analysis revealed high levels of both total and phosphorylated AURKC in MDA-MB-231 cells, in comparison with the nonmalignant cell line MCF10A. By contrast, endogenous $\mathrm{I} \kappa \mathrm{B} \alpha$ protein expression did not differ between these cell types (Supplementary Figure $5)$, although the I $\kappa \mathrm{B} \alpha$ phosphorylation level was higher in MDA-MB-231 than in MCF10A cells (Supplementary Figure 5).

To determine whether the anti-proliferative effect of AKCI is cancer cell-specific, we treated normal and cancer cells with the drug and measured proliferation using the CCK8 kit. MDA-MB-231 cells exhibited reduced proliferation when treated with $25 \mu \mathrm{M}$ AKCI for 24, 48, and $72 \mathrm{~h}$ (Figure 7D). By contrast, MCF10A cells (non-tumorigenic) exhibited no significant decrease in proliferation under the same conditions. Thus, cancer cells are more sensitive than non-tumorigenic cells to the anti-proliferative effects of AKCI.

In eukaryotes, cellular proliferation is controlled primarily by regulation of the cell cycle, which consists of four distinct sequential phases (G0/G1, S, G2, and M) [23] governed by cyclins, CDKs, and cyclin-dependent kinases. In particular, cyclin $\mathrm{B}$ and $\mathrm{CDK} 1$ proteins regulate the progression of G2/M phase [24]. Cells arrest in G2/M phase following DNA damage, and are more susceptible to the cytotoxic effects of radiotherapy at this stage of the cell cycle [25]. Induction of G2/M phase arrest promotes cell death, a useful strategy in cancer therapeutics [26]. To determine whether AKCI modulates the cell cycle in malignant breast cancer cells, we assessed the cell-cycle distribution of MDA-MB-231 cells exposed to AKCI for $24 \mathrm{~h}$. Treatment with AKCI at various concentrations arrested the cells at $\mathrm{G} 2 / \mathrm{M}$ transition (Figure $7 \mathrm{E}$ ). In addition, we examined the effect of AKCI on the expression levels of CDK1/CDC2, CDK2, cyclin B1, p21 Waf1/Cip1, p27 Kip1, and p53 in MDA-MB-231 cells. The Cip/Kip family, including p21 Waf1/Cip1 and p27 Kip1, binds to cyclin-CDK complexes and prevents kinase activation, subsequently blocking cell-cycle progression at $\mathrm{G} 2 / \mathrm{M}$ phase [27]. p53 is a transcription factor that upregulates a number of important cell cycle-modulating

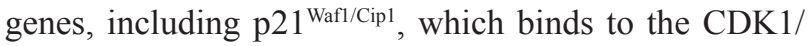
CDC2-cyclin B1 complex to induce cell-cycle arrest [7]. In MDA-MB-231 cells, the level of CDK1/CDC2 was remarkably reduced following AKCI treatment, whereas the levels of $\mathrm{p} 21^{\mathrm{Wafl} / \mathrm{Cip} 1}$ and $\mathrm{p} 53$ were markedly elevated (Figure 7F). These results suggested that AKCI, which targets AURKC, might diminish cellular transformation by inducing $\mathrm{G} 2 / \mathrm{M}$ arrest in MDA-MB-231 breast cancer cells.

Additionally, AKCI decreased PMA-induced NF$\kappa \mathrm{B}$ promoter activity in both wild-type and AURKCoverexpressing cells (Figure 7G). Therefore, AURKC overexpression might lead indirectly to NF- $\kappa \mathrm{B}$ activation, mediated by the interaction between AURKC and I $\mathrm{B} \alpha$. This aberrant activation of $\mathrm{NF}-\kappa \mathrm{B}$ could be attenuated by AKCI. 
A

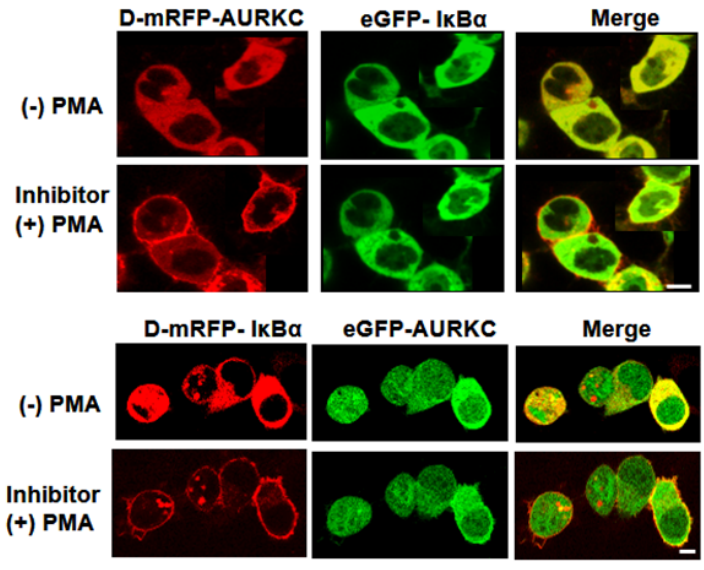

B

C

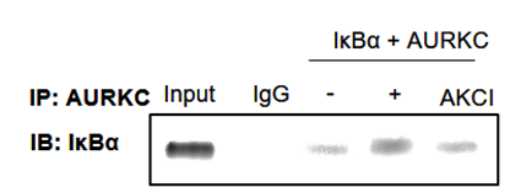

D

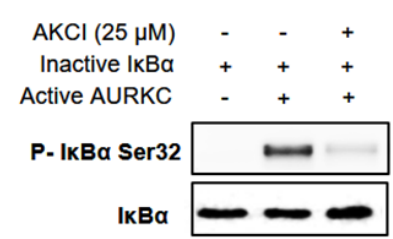

E

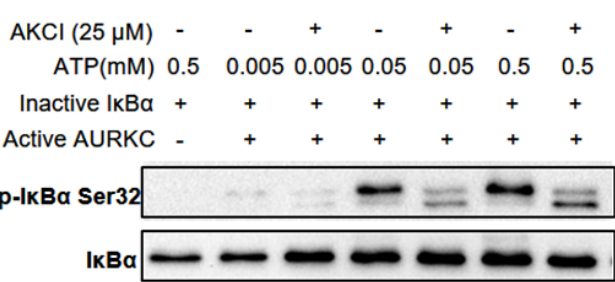

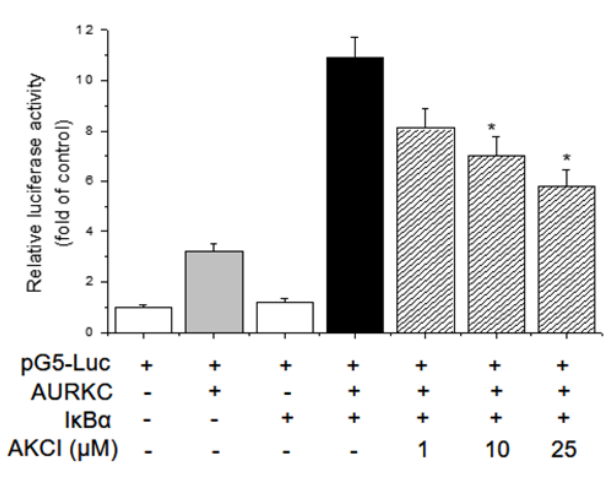

G

$\mathbf{F}$

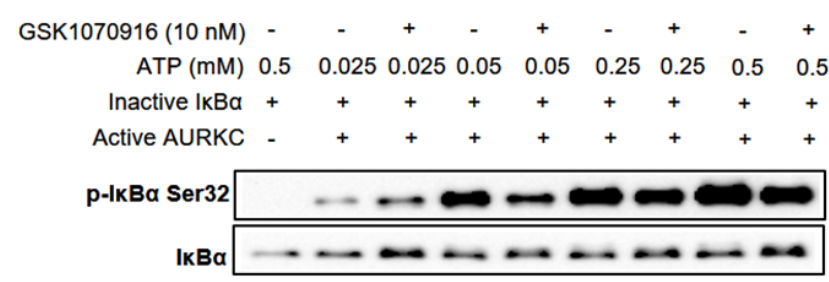

Figure 6: Effects of the small-molecule PPI inhibitor AKCI on the AURKC-IкBa interaction. (A) HEK293T cells were cotransfected with PKC $\delta$-mRFP-AURKC or I $\kappa$ B $\alpha$ (bait) and eGFP-I $\kappa \mathrm{B} \alpha$ or AURKC (prey). Cells were treated with AKCI (25 $\mu \mathrm{M})$ for $30 \mathrm{~min}$, and then with PMA (300 $\mathrm{nM})$, causing RFP-tagged protein to translocate to the membrane while GFP-tagged protein remained localized in the cytoplasm. Scale bar, $10 \mu \mathrm{m}$. (B) Cells were treated with AKCI $(25 \mu \mathrm{M})$ for $24 \mathrm{~h}$. Whole-cell lysates of HEK293T cells transfected with AURKC and I $\mathrm{B} \alpha$ were subjected to immunoprecipitation with either IgG (negative control) or anti-AURKC antibodies, followed by Western blotting of the immunoprecipitates with anti-I $\mathrm{B} \alpha$ antibodies. (C) For M2H assays, cells were transfected with pMBD-pAURKC and pVP-I $\kappa \mathrm{B} \alpha$, and then with AKCI $(1-25 \mu \mathrm{M})$. Luciferase activity is indicated as the change in relative luminescence units normalized against a negative control. $* P<0.01$, significantly different from control as determined by analysis of variance (NewmanKeuls test). (D) Inactive I $\mathrm{B} \alpha$ and active AURKC protein were incubated with AKCI $(25 \mu \mathrm{M})$, and then the mixtures were resolved by

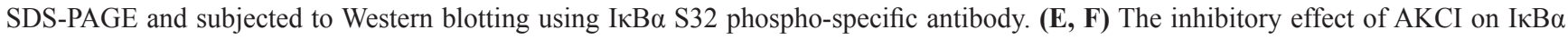
kinase activity is independent of ATP. Inactive I $\mathrm{B} \alpha$ and active AURKC protein were incubated with AKCI (25 $\mu$ M) or GSK1070916 (10 $\mathrm{nM}$ ) and various concentrations of ATP, and then the protein mixtures were subjected to Western blotting using IкB $\alpha$ S32 antibody. (G) Inactive I $\mathrm{B} \mathrm{B} \alpha$ and active AURKA protein were incubated with AKCI $(25 \mu \mathrm{M})$, and then the mixtures were resolved by SDS-PAGE and subjected to Western blotting using an I $\mathrm{B} \alpha \mathrm{S} 32$ antibody. 
A
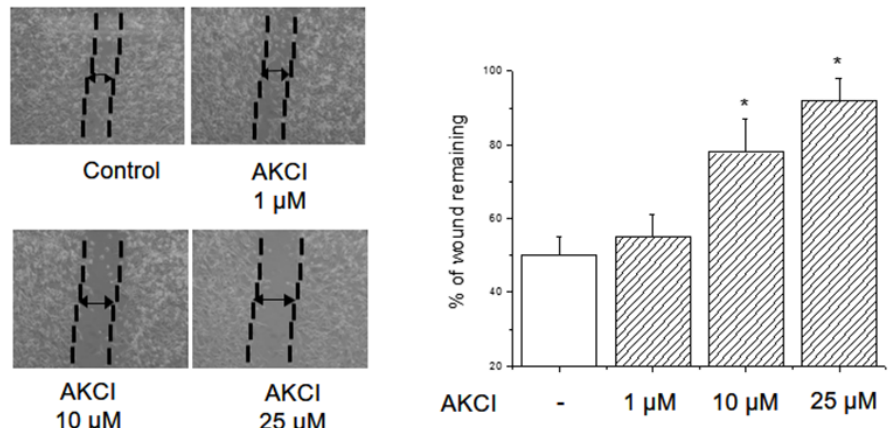

B

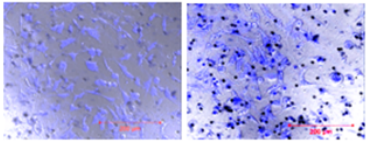

PMA
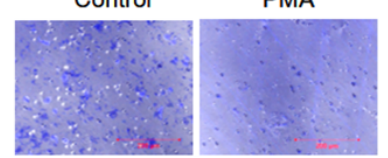

$\mathrm{AKCl}$

$\mathrm{AKCl}$

$10 \mu \mathrm{M}$

$25 \mu \mathrm{M}$

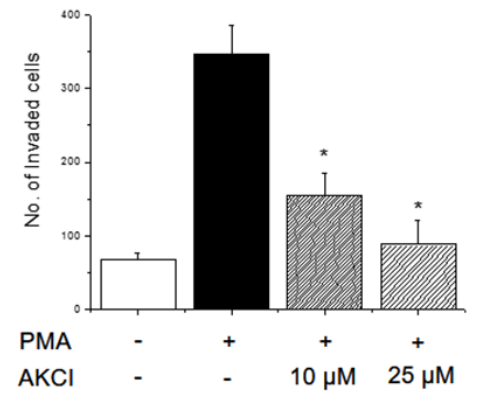

C

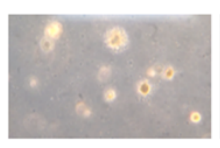

Control

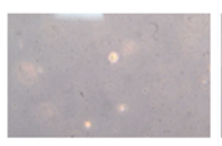

$10 \mu \mathrm{M}$

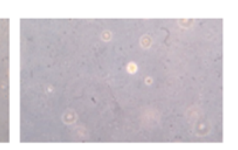

$25 \mu \mathrm{M}$

D

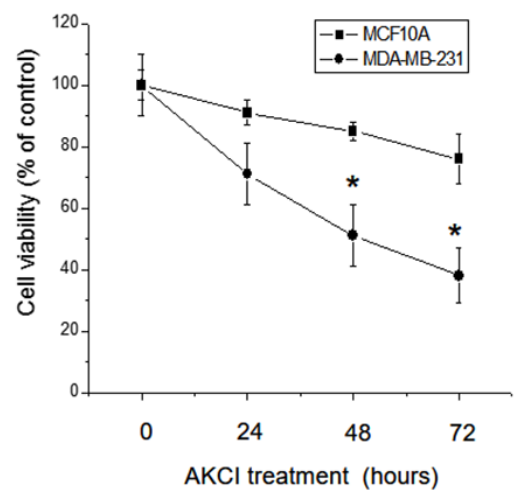

Figure 7: Inhibitory effects of AKCI on cancer cell transformation in breast cancer cells. (A) AKCI inhibits migration by MDA-MB-231. Cells were seeded into culture inserts and incubated overnight. Cell proliferation was stopped by mitomycin C treatment for $2 \mathrm{~h}$, and culture inserts were removed to introduce a cell-free gap. The cells were treated with various concentrations of AKCI for 24 $\mathrm{h}$, and cell migration was observed under a microscope. (B) AKCI inhibits invasion by MDA-MB-231. Cells were seeded into the inserts of Boyden chambers and incubated overnight. The cells were treated with the indicated doses of AKCI, and cell invasion was allowed to proceed for $24 \mathrm{~h}$. The percentage of invasive MDA-MB-231 cells was significantly reduced following AKCI treatment $\left({ }^{*} p<0.05\right)$. (C) MDA-MB-231 cells $\left(1 \times 10^{3}\right.$ cells $\left./ \mathrm{ml}\right)$ were mixed with $0.3 \%$ soft agar and grown on a $0.6 \%$ agarose base layer. Anchorage-independent colony formation was diminished by AKCI. (D) Cell viability of AKCI-treated cells. Normal MCF10A and malignant MDA-MB-231 cells were treated with $25 \mu \mathrm{M}$ AKCI for the indicated times (days), and viability was determined using the CCK8 kit. MDA-MB-231 cells were more sensitive to AKCI-mediated cell growth inhibition than MCF10A cells. ${ }^{*} P<0.01$, significantly different from control.

(Continued) 
E
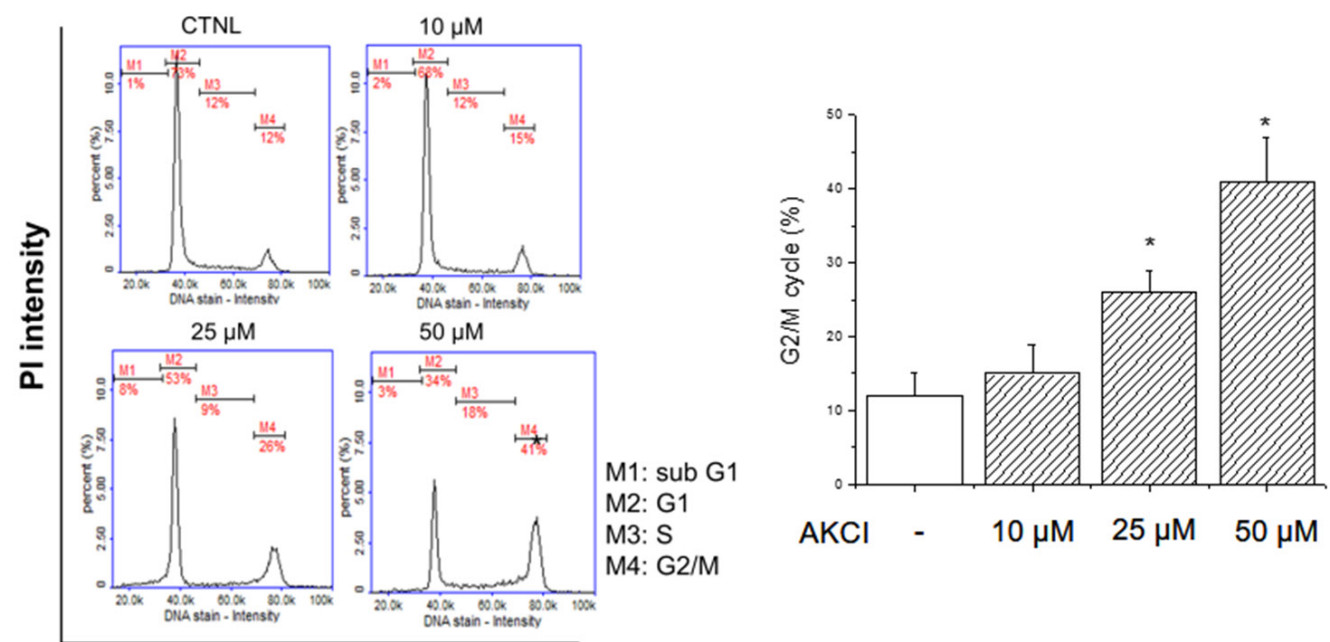

DAPI stain

$\mathbf{F}$

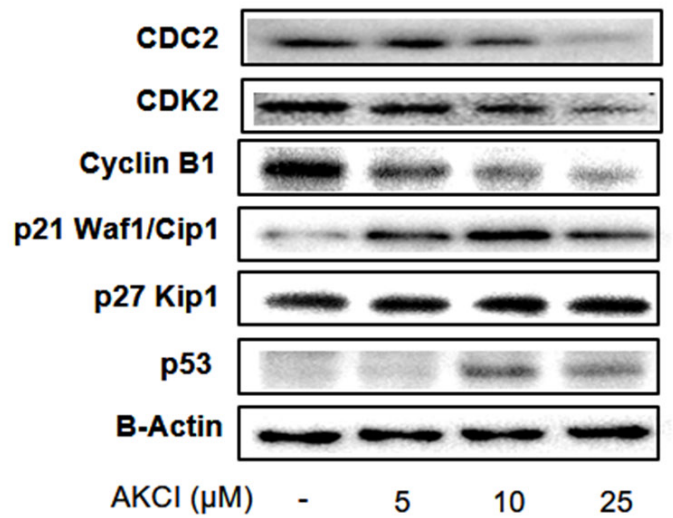

G

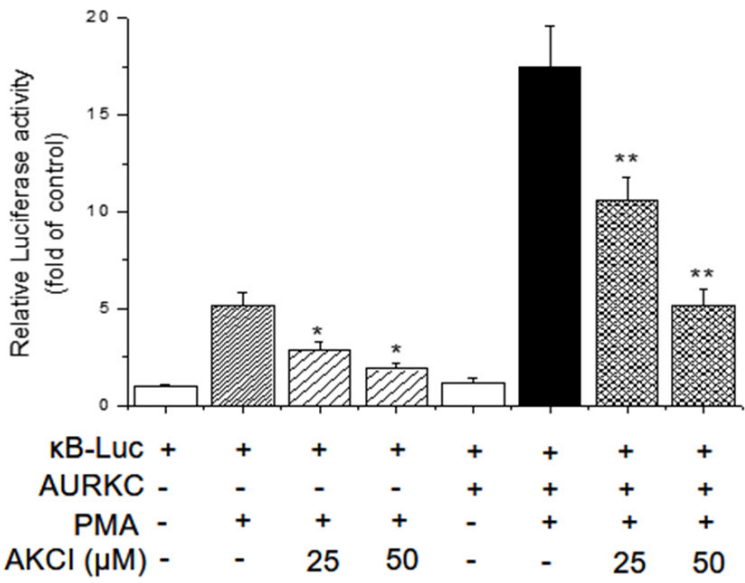

Figure 7 (Continued): (E) Effects of AKCI on cell-cycle distribution in MDA-MB-231 cells. Representative plots were presented as a result $* P<0.01$, significantly different from control G2/M cycle. (F) Effect of AKCI on expression levels of CDK1/CDC2, CDK2, cyclin B1, p2 $1^{\text {Wafl/Cipl, }}$, 27 Kip1, and p53 in MDA-MB-231 cells. Cells were treated with AKCI at 5, 10, and $25 \mu \mathrm{M}$ for $24 \mathrm{~h}$. Actin was used as the internal control. (G) Inhibitory effects of AKCI on transcriptional activity of NF- $\mathrm{kB}$. Cells were cotransfected with pGL3-NF-kBluc, pcDNA3.1-AURKC, and pCMV- $\beta$-gal, and then treated with AKCI $(10$ and $25 \mu \mathrm{M})$ for $24 \mathrm{~h}$, followed by determination of luciferase activity. ${ }^{*} P<0.01$ and $* * P<0.01$, significantly different from PMA treatment in control and AURKC-overexpressing cells. 


\section{DISCUSSION}

In normal cells, the function of AURKC is predominantly restricted to meiosis; however, it is aberrantly expressed in various cancer cell lines, and contributes to oncogenesis [28-30]. AURKC overexpression induces abnormal cell division resulting in centrosome amplification, multinucleation, and increased proliferation [31]. In addition, cells overexpressing AURKC form colony foci on soft agar, and transplantation of these cells induces tumor formation in nude mice. Recently, Zekri et al. reported amplification of the AURKC gene in MDA-MB-231 breast cancer cells [22]. However, the role of AURKC in carcinogenesis remains incompletely understood at a mechanistic level. Because AURKC is overexpressed in breast cancer cells, its PPI networks provide valuable information regarding its contribution to oncogenesis.

In this study, with the goal of elucidating the mechanistic role of AURKC in cancer cell transformation, we identified I $\mathrm{K} \mathrm{B} \alpha$ as a novel AURKC binding partner and an inhibitor capable of targeting the AURKC-IкB $\alpha$ interaction in breast cancer cells. Specifically, we screened for a small-molecule inhibitor that could control the PPI of AURKC by targeting a non-catalytic site in the interface. Such strategies have enabled drug discovery to move beyond the typical enzyme targets, such as kinases, and address disease state-relevant regulatory complexes involved in biological processes such as intracellular signal transduction and transcription. However targeting PPIs poses unique challenges, because the target's structure (i.e., the interaction site between two proteins) is often unknown, and is usually a relatively large area with physico-chemical properties distinct from those of typical catalytic sites.

We identified the interaction between AURKC and $\mathrm{I} \kappa \mathrm{B} \alpha$ by a translocation-based cellular system using fluorescence tagging plasmids, co-IP, and $\mathrm{M} 2 \mathrm{H}$ assays. Colony-forming assays revealed that $\mathrm{I} \kappa \mathrm{B} \alpha$ is essential for AURKC-induced transformation in MDA-MB-231 breast cancer cells. In vitro kinase assays revealed that AURKC kinase might induce site-specific phosphorylation of $I \kappa B \alpha$, and furthermore that the I $\mathrm{B} \alpha$ ankyrin repeat domain is important for its interaction with AURKC. Additionally, co-IP assays using an AURKC mutant indicated that His164 and Arg165 of AURKC are important for the interaction with $\mathrm{I} \kappa \mathrm{B} \alpha$ ankyrin repeat domains $\mathrm{I} / \mathrm{II} / \mathrm{III}$. In general, activation of NF- $\mathrm{KB}$ occurs by release of the transcription factor complex from I $\mathrm{B}$ molecules, or by cleavage of the inhibitory ankyrin repeat domains of p100 and $\mathrm{p} 105$ [32]. AURKC directly induces I $\mathrm{KB} \alpha$ activation via an interaction between the two proteins, leading to phosphorylation of I $\mathrm{B} \alpha$. Although AURKC alone could not induce NF- $\kappa$ B activation, NF- $\kappa$ B was activated when AURKC was overexpressed in the presence of the NF- $\kappa B$ inducer PMA.
Tumor cells can acquire elevated NF- $\kappa \mathrm{B}$ activity via intrinsic or extrinsic factors [33]. On the one hand, elevated NF- $\mathrm{\kappa B}$ activity can be directly induced by mutations of NF- $\mathrm{KB}$ genes and/or oncogenes that activate the NF- $\kappa B$ signaling pathway. On the other hand, tumor $\mathrm{NF}-\kappa \mathrm{B}$ activation can result from high levels of cytokines in the tumor microenvironment $[34,35]$. Consistent with this, the NF-KB activator PMA stimulates cytokine secretion.

Our results demonstrate that the AURKC-I $\mathrm{BB} \alpha$ interaction induces high levels of NF- $\mathrm{KB}$ activation. Moreover, we identified a novel phosphorylation site of I $\mathrm{B} \alpha$ using matrix-assisted laser desorption/ionization (MALDI) mass spectrometry (unpublished data). Hence, we postulate that AURKC-mediated serine phosphorylation of $I \kappa B \alpha$ contributes to various types of cancer cell transformation. We would like to report the role of IкB $\alpha$ in the new phosphorylation site through functional studies. Based on the domain mapping experiment (Figure 3D), we performed computational modeling and predicted a small-molecule PPI inhibitor of the AURKC-IкB $\alpha$ interaction. In silico modeling, translocation-based cellular assay using fluorescence tagging plasmids, co-IP, M2H, and in vitro kinase assays revealed that the small-molecule inhibitor AKCI inhibited binding between AURKC and I $\mathrm{I} \mathrm{B} \alpha$ by targeting a non-catalytic site of AURKC. Furthermore, AKCI inhibited migration, invasion, and colony formation by inducing $\mathrm{G} 2 / \mathrm{M}$ arrest in MDAMB-231 cells. However, AKCI had no effect on apoptosis or expression of MMP-9 (Supplementary Figures 6 and 7). Finally, AKCI inhibited PMA-induced NF-kB promoter activity, which plays pivotal roles in cancer cell transformation. Based on our results, the AURKC-I $\mathrm{KB} \alpha$ interaction represents a promising therapeutic target for treatment of breast cancer.

\section{MATERIALS AND METHODS}

\section{Materials}

Phorbol myristate acetate (PMA) was obtained from Sigma Chemical Co. (St. Louis, MO, USA), and AKCI (4, 8-dimethyl-N- \{5-[2-(4-morpholinyl)ethyl]-1, 4, 5, 6-tetrahydro-1, 3, 5-triazin-2-yl\}-2-quinazolinamine) was purchased from ChemBridge Corporation (San Diego, CA, USA). GSK1070916 was obtained from Selleck Chemicals LLC (Suffolk, UK). Fetal bovine serum (FBS), penicillin-streptomycin solution, and trypsin were obtained from Life Technologies, Inc. (Carlsbad, CA, USA). The HaloTag vector system and luciferase assay reagent were purchased from Promega (Madison, WI, USA). pCMV- $\beta$-gal and RFP antibody were obtained from Clontech (Palo Alto, CA, USA). The IкB kinase assay kit was obtained from R\&D Biosystems (Minneapolis, MN, USA), and the protein assay kit was purchased from Bio-Rad Laboratories, Inc. (Hercules, 
CA, USA). Activated AURKC and IKK $\beta$ were obtained from SignalChem (Richmond, Canada). Antibodies against AURKC and phospho-AURKC were obtained from GeneTex Inc. (San Antonio, TX, USA) and Aviva Systems Biology (San Diego, CA, USA), respectively. Antibodies against $\mathrm{I} \kappa \mathrm{B} \alpha$, phospho-I $\kappa \mathrm{B} \alpha \mathrm{S} 32$, and GFP were obtained from Santa Cruz Biotechnology (Dallas, TX, USA), and anti-phospho-I $\kappa \mathrm{B} \alpha \mathrm{S} 36$ was purchased from Abcam (Cambridge, MA, USA). Antibodies against phospho-IкB $\alpha \mathrm{S} 32 / 36, \mathrm{p} 21, \mathrm{p} 53, \mathrm{CDC} 2$, and cyclin B1, as well as secondary antibodies, were obtained from Cell Signaling Technology (Beverly, MA, USA). The BioCoat Matrigel Invasion Chamber for invasion assay was obtained from BD Sciences (San Jose, CA, USA). TurboFect was obtained from Thermo Fisher Scientific (Waltham, MA, USA). The CCK8 kit was obtained from Dojindo Laboratories (Kumamoto, Japan).

\section{Cell culture and treatment}

The normal breast cell line MCF10A and MDAMB-231 breast cancer cells were obtained from the American Type Culture Collection (Rockville, MD, USA). HEK293T cells were obtained from the Korean Cell Line Bank (Seoul, South Korea). All cells were cultured in Dulbecco's modified Eagle's medium (DMEM), high glucose, supplemented with $10 \% \mathrm{FBS}$, in a humidified $5 \% \mathrm{CO}_{2}$ incubator at $37^{\circ} \mathrm{C}$. Stock solutions of PMA and $\mathrm{A} / \mathrm{I}$ inhibitor $(\mathrm{AKCI})$ were prepared in dimethylsulfoxide (DMSO) and added directly to culture media. Control cells were treated only with DMSO, and the final DMSO concentration was always $<0.2 \%$.

\section{Molecular cloning and transfection of HEK293T cells}

The C-terminal fusion constructs $\mathrm{PKC} \delta /$ monomeric red fluorescent protein (mRFP)/AURKC and /I $\mathrm{B} \alpha$ (bait) were generated using the EcoRI and BamHI restriction site in $\mathrm{C}$-terminal fusion constructs $\mathrm{PKC} \delta /$ monomeric red fluorescent protein (mRFP) [17]. For analysis of PPI, the cDNAs of 520 human kinases were amplified by PCR and introduced into the mammalian expression plasmid pEGFP-C3. Human AURKC cDNA was subcloned into the EcoRI and BamHI sites of vector pcDNA3.1. The following primers were used for molecular cloning: $\mathrm{PKC} \delta$ $\mathrm{mRFP} / \mathrm{pEGFP}$ and pCDNA3.1-AURKC (forward) 5' -gct gaattctgatgcggcgcctcacagtcg-3'; $\mathrm{PKC} \delta$-mRFP/pEGFP, $\mathrm{PKC} \delta$-mRFP/pEGFP, and pCDNA3.1-AURKC (reverse) 5'-gctggatcctaggaagccatctgagcacag-3'; PKC $\delta$-mRFP/ pEGFP-I $\kappa \mathrm{B} \alpha$ (forward) 5' -gaagaattctgatgttccaggcggccga gcg-3'; and PKC $\delta$-mRFP/pEGFP-IкB $\alpha$ (reverse) 5'-gaag gattccgtcataaacgtcagacgctggcctccaa-3'. All positive clones containing cDNA inserts were confirmed by restriction enzyme mapping and DNA sequence analysis (Cosmo Genetech, Daejeon, South Korea).

\section{Analysis of PPI and small-molecule inhibitor targeting of PPI by laser scanning fluorescence microscopy imaging}

HEK293T cells were cotransfected with $\mathrm{PKC} \delta$ mRFP-AURKC (bait) and eGFP-prey protein (520 kinases, including $\mathrm{I} \kappa \mathrm{B} \alpha$ ). Fluorescence images were acquired on a confocal laser scanning fluorescence microscope (LSM710, Carl Zeiss) equipped with a 40× objective. Images were analyzed using the ZEN2009 software (Carl Zeiss).

\section{Co-immunoprecipitation (co-IP)}

HEK293T cells were cotransfected with pcDNA3.1AURKC myc-his and pCMV6-IkB myc-Flag using TurboFect (Thermo Fisher Scientific). Twenty-four hours after transfection, cells were washed with $1 \times$ PBS and lysed with $1 \mathrm{ml}$ of IP lysis buffer (50 mM Tris $\mathrm{pH}$ 7.4, $150 \mathrm{mM} \mathrm{NaCl}, 1 \mathrm{mM}$ EDTA, 0.5\% NP-40, 5\% glycerol) supplemented with protease inhibitor cocktail mix (Roche). Cell lysates were pre-cleared by preincubation with protein A-Sepharose 4 Fast Flow beads (GE Healthcare) for $30 \mathrm{~min}$, and then incubated for $2 \mathrm{~h}$ with fresh beads and 1:200 dilutions of anti-I $\mathrm{B} \alpha$, antiAURKC, and anti-goat IgG antibodies. The beads were washed once with IP lysis buffer and twice with PBS, and the immune complexes were released from the beads by boiling in sample buffer for $5 \mathrm{~min}$. Following $10 \%$ SDS-PAGE, immunoprecipitates were transferred onto polyvinylidene difluoride (PVDF) membrane and immunoblotted using the indicated antibodies. Proteins were visualized using the enhanced chemiluminescence (ECL) detection system (GE Healthcare).

\section{Mammalian two-hybrid assay}

For transfections, equal amounts of plasmids pBIND-AURKC, pACT-I $\mathrm{BB} \alpha$, and pG5-luciferase were combined; the total amount of DNA was no more than $100 \mathrm{ng} /$ well. Transfections were performed with TurboFect. Cells were disrupted by addition of $200 \mu \mathrm{l}$ of cell lysis buffer directly into each well of the 48-well plate, and then aliquots of $70 \mu \mathrm{l}$ were added to individual wells of a 96-well luminescence plate. Luminescence activity was measured automatically on a SpectraMax M5 microplate reader (Molecular Devices). Relative luciferase activity was calculated by normalization against the pG5luciferase basal control. Renilla luciferase activity assay was used for assessment of transfection efficiency and protein level.

\section{In situ proximity ligation assay (PLA)}

Cells were seeded onto 24-well plates with glass coverslips at the bottom of each well. After 
transfection of target vectors, cells were fixed in $4 \%$ paraformaldehyde for $5 \mathrm{~min}$, and then washed four times with PBS. Cover glasses were attached to glass slides using Canada Balsam (Sigma Chemical Co, St. Louis, MO, USA) to facilitate the manipulations in the next step. All steps of the Duo-Link (Promega, Madison, WI, USA) protocol were performed as open-droplet reactions on the cover glass to ensure complete coverage of the cells. Primary antibodies against AURKC and I $\kappa \mathrm{B} \alpha$ were diluted 1:100 in Duo-Link antibody diluent solution, applied to the cover glass. The next day, the slides were washed three times in Duo-Link wash buffer A to remove excess antibody. After washing, antibodyoligonucleotide conjugates were applied to cells for 2 $\mathrm{h}$ and ligated for $30 \mathrm{~min}$ at $37^{\circ} \mathrm{C}$ in Duo-Link ligation mixture. Subsequently, ligated templates were amplified in Duo-Link amplification mixture for $100 \mathrm{~min}$ at $37^{\circ} \mathrm{C}$. After the reaction, the samples were washed twice for $10 \mathrm{~min}$ in Duo-Link wash buffer B and once for 1 min in $0.1 \times$ wash buffer $B$, and then mounted with ProLong Diamond Antifade Mountant with DAPI (Life Technologies, Carlsbad, CA, USA). Image acquisition was performed on a Zeiss 710 confocal microscope under $4 \times$ magnification.

\section{Cell-based ELISA of ІкBa}

I $\mathrm{B} \alpha$ activation was examined using a cellbased ELISA phospho-IкB $\alpha \quad(\mathrm{S} 32 / \mathrm{S} 36)$ assay kit (R\&D Biosystems). Briefly, HEK293T cells were seeded in black 96-well plates, and then transfected with AURKC expression vector and shRNA (CCACGATAATAGAGGAGTTGGCAGATGCC) for $24 \mathrm{~h}$. Subsequently, the cells were fixed and incubated with primary and secondary antibodies. After addition of substrate, fluorescence was detected on a SpectraMax M5 microplate reader.

\section{Purification of IкB $\alpha$ protein using the HaloTag system}

Full-length human $\mathrm{I} \kappa \mathrm{B} \alpha$ was cloned into vector pFN18A (Promega), and the resultant plasmid was transformed into KRX cells (Promega) grown in LB media (+ampicillin) supplemented with glucose and rhamnose to induce expression without isopropyl- $\beta$-D-thiogalactoside (IPTG). After the cells reached an $\mathrm{OD}_{600}$ of $0.5-0.6$ at $37^{\circ} \mathrm{C}$, the temperature was reduced to $20^{\circ} \mathrm{C}$ for overnight expression. For $\mathrm{I} \kappa \mathrm{B} \alpha$ purification, cell pellets were resuspended in $5 \mathrm{ml}$ of HaloTag purification buffer (50 $\mathrm{mM}$ HEPES [pH 7.5] and $150 \mathrm{mM} \mathrm{NaCl}$ ) supplemented with $1 \times$ Protease Inhibitor (Thermo Fisher Scientific), and then sonicated on ice using a Vibra cell sonicator (5 min total on time; $1 \mathrm{~min}$ on/ $1 \mathrm{~min}$ off; amplitude $=40-60$, pulse $=4$ ). Lysates were centrifuged at $10,000 \mathrm{~g}$ for 30 min at $4^{\circ} \mathrm{C}$, and the supernatants were directly applied to pre-equilibrated HaloLink resin (Promega). Binding to the resin was conducted at room temperature for $1 \mathrm{~h}$ with constant end-over-end rotation, followed by three washes in $10 \mathrm{ml}$ of purification buffer for $5 \mathrm{~min}$ each. Target proteins were released from the resin by proteolytic cleavage using a Halo TEV enzyme for $1 \mathrm{~h}$ at room temperature. Supernatants containing the released protein of interest and TEV protease were carefully transferred to a new tube. To remove TEV protease, HisLink resin was added to the tube and allowed to bind at room temperature for $20 \mathrm{~min}$ with constant end-over-end rotation. After centrifugation at $1,000 \mathrm{~g}$ for $5 \mathrm{~min}$, the supernatant was transferred to another tube. To determine purity, purified proteins were resolved by SDS-PAGE, and gels were stained with Coomassie Brilliant Blue (Thermo Fisher Scientific).

\section{Immunoblotting and kinase assays}

The I $\mathrm{BB} \alpha$ full-length (1-317 aa) and deletion constructs (1-175, 1-277, and 1-72/278-317 aa) were amplified by PCR and cloned into the HaloTag pFN18A plasmid. The I $\mathrm{I} B \alpha \mathrm{S} 32 \mathrm{~A}, \mathrm{~S} 36 \mathrm{~A}$, and S32/36A, and AURKC H164Y, mutations were introduced using the QuikChange Lightning site-directed mutagenesis kit (Stratagene, Santa Clara, CA, USA). Recombinant active AURKC (100 ng) protein and substrate I $\mathrm{B} \mathrm{B} \alpha$ or $\mathrm{I} \kappa \mathrm{B} \alpha$ mutant (S32A, S36A, S32/36A, 1-175 aa, 1-277 aa, or 1-72/278-317 aa) were incubated in the presence or absence of AKCI for $10 \mathrm{~min}$ at $30^{\circ} \mathrm{C}$. The mixture was suspended in kinase buffer supplemented with $10 \mu \mathrm{l}$ of diluted ATP solution. Protein complexes were resolved by $10 \%$ SDS-PAGE, followed by electroblotting onto PVDF membranes. The membranes were probed with the appropriate primary antibodies, followed by incubation with horseradish peroxidase-conjugated secondary antibody. The blots were visualized using the ECL Western blot kit.

\section{Establishment of AURKC-overexpressing and -knockdown cell lines}

Viral supernatants were applied to MDAMB-231 cells in 6-well plates overnight in the presence of LentiBoost (Sirion Biotech $\mathrm{GmbH}$, Martinsried, Germany). After infection, MDA-MB-231 cells were selected for $48 \mathrm{~h}$ with $2 \mu \mathrm{g} / \mathrm{ml}$ puromycin, and then sorted by GFP intensity on a MoFlo Astrios flow cytometer (Beckman Coulter, USA). Validation of GFP-positive cells was performed by confocal microscopy (LSM710, Carl Zeiss).

\section{Binding model prediction of AURKC and IкBa}

The model of I $\kappa \mathrm{B} \alpha-\mathrm{AURKC}$ binding was generated using the ZDOCK tool in Discovery Studio 
4.5 (BIOVIA). The structure of $\mathrm{I} \kappa \mathrm{B} \alpha$ was obtained from the Protein Data Bank (PDB code: 1ikn). The homology model of the AURKC structure was constructed using MODELLER in Discovery Studio4.5, using the structure of AURKA (PDB code: $2 \mathrm{j} 4 \mathrm{z}$ ) as a template. The initial I $\kappa \mathrm{B} \alpha$ and AURKC structures were minimized by the steepest-descent method for 5,000 iterations using the CHARMm force field. The AURKC-I $\mathrm{BB} \alpha$ docking model were generated top 2,000 predictions for each case and it was generated using ZDOCK at a $6^{\circ}$ rotational sampling density with each of the scoring functions. Finally, the top-scoring cluster was selected as the model for the AURKC-IкB $\alpha$ complex.

\section{Docking model prediction of AURKC-IKB $\alpha$ interaction inhibitor}

To generate a binding model of the AURKC-I $\mathrm{B} \mathrm{B} \alpha$ interaction inhibitor, the homology model structure of AURKC was subjected to in silico docking with AKCI. The protein structure was prepared according to the standard procedure for the Protein Preparation Wizard in Schrödinger suite 2015-2. After complete preparation of ligands and protein for docking, receptor-grid files were generated. Ligand docking into the AURKC-I $\mathrm{I} \mathrm{B} \alpha$ binding interface site was carried out using the Schrödinger docking program, Glide. The energy-minimized AURKC$\mathrm{I} \kappa \mathrm{B} \alpha$ interaction inhibitor was docked into the prepared receptor grid. The best-docked pose was selected based on the lowest Glide score. The molecular graphics for the inhibitor-binding pocket and refined docking model for the AKCI were generated using PyMol (http://www. pymol.org).

\section{Virtual screening}

To identify compounds that inhibit the AURKC$\mathrm{I} \kappa \mathrm{B} \alpha$ interaction by binding the PPI, a docking-based virtual screen of the AURKC-I $\mathrm{B} \mathrm{B} \alpha$ binding interface was performed using Glide. The HTVS (High Throughput Virtual Screening) and SP (Standard Precision) scoring functions were used, granting full flexibility to the ligands. The top-ranking SP poses of each compound were selected. The compound dataset used for the virtual screening experiments was a commercially available chemical library (http://www.chembridge.com, 728,435 molecules).

\section{Assay for proliferative activity}

Cell cytotoxicity was monitored using a Cell Counting Kit-8 (CCK8, Dojindo Laboratories). Briefly, MDA-MB-231 cells in DMEM, high glucose, containing $10 \%$ FBS were seeded into 96-well plates. AKCI $(25 \mu \mathrm{M})$ was added to the wells, and the plates were incubated at $37^{\circ} \mathrm{C}$ for 24,48 , or $72 \mathrm{~h}$. CCK8 solution was added $(10 \mu \mathrm{l}$ per well), and the plates were incubated for $1-4 \mathrm{~h}$ at $37^{\circ} \mathrm{C}$. Absorbance was detected at $450 \mathrm{~nm}$ with a SpectraMax M5 microplate reader. All experiments were repeated three times independently.

\section{Cell migration and invasion assay}

MDA-MB-231 cells were seeded into 24-well plates and cultured overnight. The cells were treated with mitomycin $\mathrm{C}(10 \mu \mathrm{g} / \mathrm{ml})$ for $2 \mathrm{~h}$, and the culture inserts were removed to open a cell-free gap. The cells were treated with the indicated doses of AKCI or PMA for $24 \mathrm{~h}$, and cell migration was observed under a light microscope. The migrated area was measured using the ImageJ software (v. 1.45). The effect of $\mathrm{A} / \mathrm{I}$ inhibitor on cancer cell invasion was measured using a Matrigel-coated invasion chamber (Corning Incorporated, Corning, NY, USA). Briefly, $1 \times 10^{4}$ MDA-MB-231 cells were seeded into an insert chamber with FBS-free media, supplemented with the indicated doses of $\mathrm{A} / \mathrm{I}$ inhibitor (AKCI), and cultured in 24-well plates supplemented with complete media for the indicated times. The cells were fixed with $4 \%$ formaldehyde, permeabilized with methanol, and stained with crystal violet. The stained cells were observed under a light microscope, and those that had migrated were counted.

\section{Soft agar assay}

For the soft agar assay, cells were trypsinized to generate single-cell suspensions and counted. 1.2\% agarose (Promega, Madison, WI, USA) dissolved in medium was plated on the bottom of each well. Single-cell suspensions (1,000 cells per well) were mixed with $0.6 \%$ agarose and seeded on top of the bottom agar. All assays were performed in triplicate. The cells were incubated at $37^{\circ} \mathrm{C}$ for 6 weeks to allow colony formation. Images were captured using a Zeiss inverted wide-field microscope equipped with a Canon G12 camera.

\section{Colony formation assay}

Cells were seeded in 6-well plates at 1,000 cells/ well and cultured for 8 days to allow colony formation. After incubation, cells were washed with PBS, stained with $0.1 \%$ crystal violet (AMRESCO, Solon, OH, USA) in $50 \%$ methanol, and counted.

\section{Cell-cycle analysis}

Cells were treated with AKCI and then trypsinized, washed with PBS, and subjected to cell-cycle analysis on a NucleoCounter NC-3000 (ChemoMetec, Allerød, Denmark). Two-step analysis was performed in which the cells were lysed and the nuclei were stained with DAPI [18]. 


\section{Transient transfection and the NF-кB luciferase assay}

HEK293T cells were transiently transfected with the NF- $\mathrm{kB}$ promoter-luciferase construct and pcDNA3.1AURKC using the TurboFect reagent. After overnight transfection, cells were incubated with PMA or AKCI for $24 \mathrm{~h}$, and whole-cell lysates were prepared. Whole-cell extract $(70 \mu \mathrm{l})$ was mixed with $70 \mu \mathrm{l}$ of the luciferase assay reagent and analyzed on a SpectraMax M5 luminometer.

\section{Statistical analysis}

All experiments were repeated at least three times. One-way analysis of variance (ANOVA) was used to determine the significance of differences between treatment groups. The Newman-Keuls test was used for multi-group comparisons. Statistical significance was defined as $p<0.01$.

\section{CONFLICTS OF INTEREST}

The authors declare no conflicts of interest.

\section{GRANT SUPPORT}

This research was supported by the Creative Fusion Research Program through the Creative Allied Project funded by the Korea Research Council of Fundamental Science and Technology (CAP-12-1); a National Research Foundation of Korea Grant funded by the Korean Government (MSIP) (2014, R\&D Equipment Engineer Education Program, 2013R1A6A9067028); and a grant from the Korea Basic Science Institute (D36402, T36415). This research was also supported by the Main Research Program (E0164403-02) of the Korea Food Research Institute (KFRI) funded by the Ministry of Science, ICT, \& Future Planning.

\section{REFERENCES}

1. Gaffan J, Dacre J, Jones A. Educating undergraduate medical students about oncology: a literature review. J Clin Oncol. 2006; 24:1932-9.

2. Kasami M, Uematsu T, Honda M, Yabuzaki T, Sanuki J, Uchida Y, Sugimura H. Comparison of estrogen receptor, progesterone receptor and Her-2 status in breast cancer preand post-neoadjuvant chemotherapy. Breast. 2008; 17:523-7.

3. Morgan G, Ward R, Barton M. The contribution of cytotoxic chemotherapy to 5-year survival in adult malignancies. Clin Oncol (R Coll Radiol). 2004; 16:549-60.

4. Okada H, Mak TW. Pathways of apoptotic and nonapoptotic death in tumour cells. Nat Rev Cancer. 2004; 4:592-603.
5. Fu J, Bian M, Jiang Q, Zhang C. Roles of Aurora kinases in mitosis and tumorigenesis. Mol Cancer Res. 2007; 5:1-10.

6. Barr AR, Gergely F. Aurora-A: the maker and breaker of spindle poles. J Cell Sci. 2007; 120:2987-96.

7. Li JP, Yang YX, Liu QL, Pan ST, He ZX, Zhang X, Yang T, Chen XW, Wang D, Qiu JX, Zhou SF. The investigational Aurora kinase A inhibitor alisertib (MLN8237) induces cell cycle G2/M arrest, apoptosis, and autophagy via p38 MAPK and Akt/mTOR signaling pathways in human breast cancer cells. Drug Des Devel Ther. 2015; 9:1627-52.

8. Green MR, Woolery JE, Mahadevan D. Update on aurora kinase targeted therapeutics in oncology. Expert Opin Drug Discov. 2011; 6:291-307.

9. Lok W, Klein RQ, Saif MW. Aurora kinase inhibitors as anti-cancer therapy. Anticancer Drugs. 2010; 21:339-50.

10. Carmena M, Earnshaw WC. The cellular geography of aurora kinases. Nat Rev Mol Cell Biol. 2003; 4:842-54.

11. Slattery SD, Mancini MA, Brinkley BR, Hall RM. Aurora-C kinase supports mitotic progression in the absence of Aurora-B. Cell Cycle. 2009; 8:2984-94.

12. Khan J, Ezan F, Cremet JY, Fautrel A, Gilot D, Lambert M, Benaud C, Troadec MB, Prigent C. Overexpression of active Aurora-C kinase results in cell transformation and tumour formation. PLoS One. 2011; 6:e26512.

13. Mobasheri MB, Shirkoohi R, Zendehdel K, Jahanzad I, Talebi S, Afsharpad M, Modarressi MH. Transcriptome analysis of the cancer/testis genes, DAZ1, AURKC, and TEX101, in breast tumors and six breast cancer cell lines. Tumour Biol. 2015; 36:8201-6.

14. Ivanov AA, Khuri FR, Fu H. Targeting protein-protein interactions as an anticancer strategy. Trends Pharmacol Sci. 2013; 34:393-400.

15. Sheng C, Dong G, Miao Z, Zhang W, Wang W. State-ofthe-art strategies for targeting protein-protein interactions by small-molecule inhibitors. Chem Soc Rev. 2015; 44:8238-59.

16. Jin L, Wang W, Fang G. Targeting protein-protein interaction by small molecules. Annu Rev Pharmacol Toxicol. 2014; 54:435-56.

17. Arkin MR, Tang Y, Wells JA. Small-molecule inhibitors of protein-protein interactions: progressing toward the reality. Chem Biol. 2014; 21:1102-14.

18. Lee KB, Hwang JM, Choi IS, Rho J, Choi JS, Kim GH, Kim SI, Kin S, Lee ZW. Direct monitoring of the inhibition of protein-protein interactions in cells by translocation of PKCdelta fusion proteins. Angew Chem Int Ed Engl. 2011; 50:1314-7.

19. Myklebust MP, Bruland O, Fluge O, Skarstein A, Balteskard L, Dahl O. MicroRNA-15b is induced with E2Fcontrolled genes in HPV-related cancer. Br J Cancer. 2011; 105:1719-25.

20. Nishikori M. Classical and alternative NF-kB activation pathways and their roles in lymphoid malignancies. J Clin Exp Hematopathol. 2005; 45:1. 
21. Briassouli P, Chan F, Linardopoulos S. The N-terminal domain of the Aurora-A Phe-31 variant encodes an E3 ubiquitin ligase and mediates ubiquitination of IkappaBalpha. Hum Mol Genet. 2006; 15:3343-50.

22. Zekri A, Lesan V, Ghaffari SH, Tabrizi MH, Modarressi $\mathrm{MH}$. Gene amplification and overexpression of Aurora-C in breast and prostate cancer cell lines. Oncol Res. 2012; 20:241-50.

23. Hengartner MO. The biochemistry of apoptosis. Nature. 2000; 407:770-6.

24. Cho HJ, Oh YJ, Han SH, Chung HJ, Kim CH, Lee NS, Kim WJ, Choi JM, Kim H. Cdk1 protein-mediated phosphorylation of receptor-associated protein 80 (RAP80) serine 677 modulates DNA damage-induced G2/M checkpoint and cell survival. J Biol Chem. 2013; 288:3768-76.

25. Pawlik TM, Keyomarsi K. Role of cell cycle in mediating sensitivity to radiotherapy. Int J Radiat Oncol Biol Phys. 2004; 59:928-42.

26. Montenegro MF, Sanchez-del-Campo L, Fernandez-Perez MP, Saez-Ayala M, Cabezas-Herrera J, Rodriguez-Lopez JN. Targeting the epigenetic machinery of cancer cells. Oncogene. 2015; 34:135-43.

27. Sancar A, Lindsey-Boltz LA, Unsal-Kacmaz K, Linn S. Molecular mechanisms of mammalian DNA repair and the DNA damage checkpoints. Annu Rev Biochem. 2004; 73:39-85.
28. Balboula AZ, Schindler K. Selective disruption of aurora $\mathrm{C}$ kinase reveals distinct functions from aurora B kinase during meiosis in mouse oocytes. PLoS Genet. 2014; 10:e1004194.

29. Hassold T, Chiu D. Maternal age-specific rates of numerical chromosome abnormalities with special reference to trisomy. Hum Genet. 1985; 70:11-7.

30. Hassold T, Hall H, Hunt P. The origin of human aneuploidy: where we have been, where we are going. Hum Mol Genet. 2007; 16:R203-8.

31. Goldenson B, Crispino JD. The aurora kinases in cell cycle and leukemia. Oncogene. 2015; 34:537-45.

32. Hoesel B, Schmid JA. The complexity of NF- $\mathrm{kB}$ signaling in inflammation and cancer. Mol Cancer. 2013; 12:86.

33. Mantovani A, Allavena P, Sica A, Balkwill F. Cancer-related inflammation. Nature. 2008; 454:436-44.

34. Ben-Neriah Y, Karin M. Inflammation meets cancer, with $\mathrm{NF}-\kappa \mathrm{B}$ as the matchmaker. Nat Immunol. 2011; 12:715-23.

35. Greten FR, Eckmann L, Greten TF, Park JM, Li ZW, Egan LJ, Kagnoff MF, Karin M. IKKbeta links inflammation and tumorigenesis in a mouse model of colitis-associated cancer. Cell. 2004; 118:285-96. 